\title{
WestVirginiaUniversity
}

THE RESEARCH REPOSITORY @ WVU

Graduate Theses, Dissertations, and Problem Reports

2007

\section{Market risk analysis of coal liquefaction}

Huan Mei

West Virginia University

Follow this and additional works at: https://researchrepository.wvu.edu/etd

\section{Recommended Citation}

Mei, Huan, "Market risk analysis of coal liquefaction" (2007). Graduate Theses, Dissertations, and Problem Reports. 2560.

https://researchrepository.wvu.edu/etd/2560

This Thesis is protected by copyright and/or related rights. It has been brought to you by the The Research Repository @ WVU with permission from the rights-holder(s). You are free to use this Thesis in any way that is permitted by the copyright and related rights legislation that applies to your use. For other uses you must obtain permission from the rights-holder(s) directly, unless additional rights are indicated by a Creative Commons license in the record and/ or on the work itself. This Thesis has been accepted for inclusion in WVU Graduate Theses, Dissertations, and Problem Reports collection by an authorized administrator of The Research Repository @ WVU. For more information, please contact researchrepository@mail.wvu.edu. 


\title{
Market Risk Analysis of Coal Liquefaction
}

\author{
Huan Mei
}

Thesis submitted to the Davis College of Agriculture, Forestry, and Consumer Sciences at West Virginia University

in partial fulfillment of the requirements

for the degree of

Master of Science

In

Agricultural and Resource Economics

Jerald J. Fletcher, Ph.D., Chair

Alan R. Collins, Ph.D.

Mark Sperow, Ph.D.

Qingyun Sun, Ph.D.

Haixiao Huang, Ph.D.

Department of Agricultural and Resource Economics

\author{
Morgantown, West Virginia \\ 2007
}

Keywords: Coal Liquefaction, Market Risk, West Virginia 


\section{Abstract \\ Market Risk Analysis of Coal Liquefaction \\ Huan Mei}

This study addresses the risks associated with coal liquefaction using a market risk simulation approach. The study can be divided into four phases: (i) identify the sources of risk, (ii) examine the relationships among different sources that cause the risk, (iii) estimate the risk level based on the sources of risk using statistical and financial method and (iv) provide conclusions and recommendations for risk analysis.

Market risk is considered the most important risk for commercial scale coal liquefaction projects and is one of the biggest obstacles to commercialization. This study analyses market risk and discusses methods to lower this type of risk. For a coal liquefaction project, the relationship between coal and oil prices has a critical influence on the project's feasibility. This study also extends the relationship among different types of risks of coal liquefaction and provides guidelines for risk management.

In the risk assessment section, statistical and financial methods are applied to analyze the risk of a proposed coal liquefaction project in West Virginia. Granger Causality Tests are conducted to examine the relationship between coal and oil prices. Using the estimated standard errors, Monte Carlo simulations of NPV are performed to access the financial viability of the West Virginia coal liquefaction project. The results show that the project has a high probability of financial feasibility including a high expected net present value with an acceptable standard deviation. Conclusions and extended discussions are based on the simulation results. 


\section{Acknowledgments}

I’d like to thank Dr. Fletcher, Dr. Collins, Dr. Sperow, Dr. Qingyun Sun and Dr. Haixiao Huang. Thank you for you guys continuous support and guidance. Also, I want to thank U.S. Department of Energy for supporting me a couple of years at West Virginia University and I really appreciate that.

My sincere thanks to all of the family and friends who listened to all the woes and joys I felt through the process.

Acknowledgment: "This material is based upon work supported by the Department of Energy under Award Number DE-FC26-06NT42804.

Disclaimer: "This report was prepared as an account of work sponsored by an agency of the United States Government. Neither the United States Government nor any agency thereof, nor any of their employees, makes any warranty, express or implied, or assumes any legal liability or responsibility for the accuracy, completeness, or usefulness of any information, apparatus, product, or process disclosed, or represents that its use would not infringe privately owned rights. Reference herein to any specific commercial product, process, or service by trade name, trademark, manufacturer, or otherwise does not necessarily constitute or imply its endorsement, recommendation, or favoring by the United States Government or any agency thereof. The views and opinions of authors expressed herein do not necessarily state or reflect those of the United States Government or any agency thereof.” 


\section{Table of Contents}

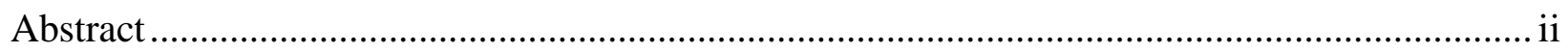

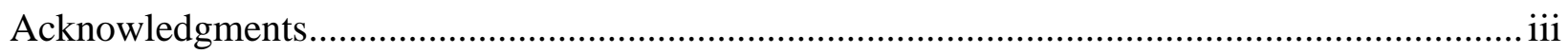

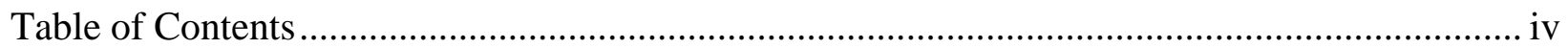

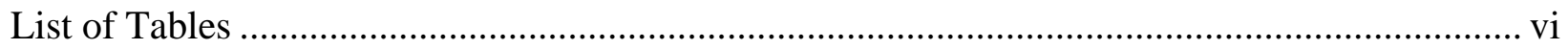

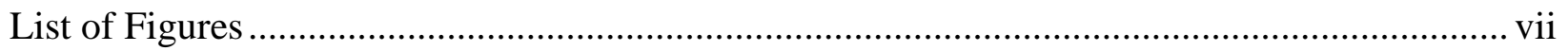

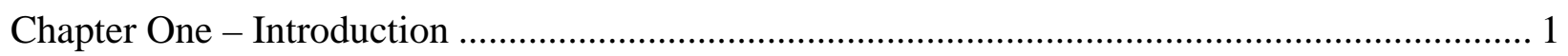

1.1 Problem Statement .................................................................................................... 1

1.2 Objectives of the Study ……………………………….......................................... 2

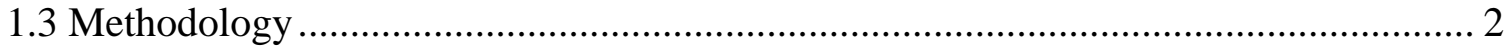

1.4 Outline for the Study............................................................................................ 2

Chapter Two - Coal Liquefaction Fundamentals ………........................................................... 4

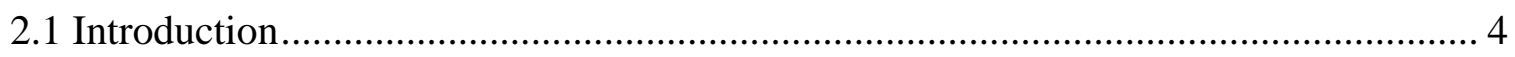

2.2 Coal Liquefaction Technology ………………....................................................... 4

2.3 The Significance of Coal Liquefaction ……………….............................................. 6

2.4 The History of Coal Liquefaction ................................................................................ 10

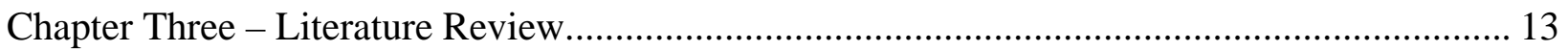

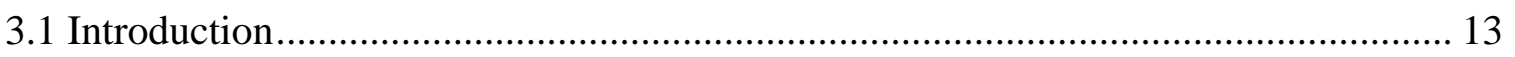

3.2 Risks Associated with Coal Liquefaction ................................................................ 13

3.3 Risk Analysis Methods ..................................................................................... 15

3.4 Tools for Risk Analysis ....................................................................................... 17

Chapter Four - Risk Associated with Coal Liquefaction ........................................................... 20

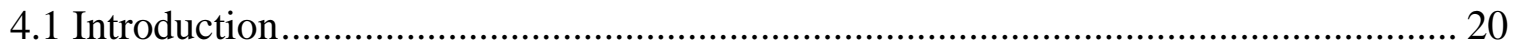

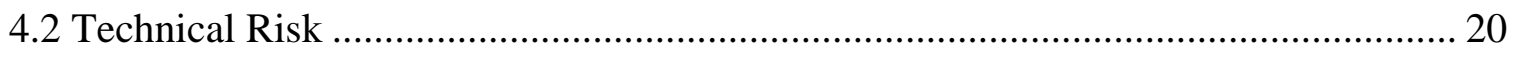

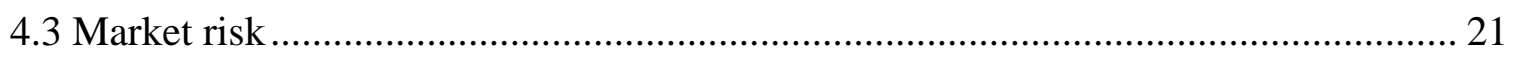

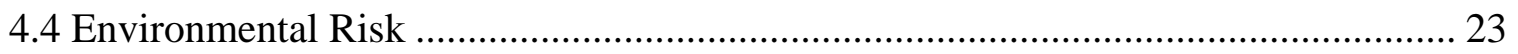

4.5 Commercialization and Operating Risk................................................................... 25

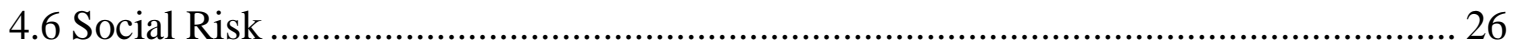

Chapter Five - West Virginia Coal Conversion Project Risk Analysis............................................ 27

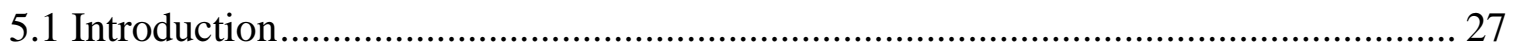

5.2 The Relationship between Coal and Oil Prices........................................................... 27

5.3 West Virginia Coal Conversion Project Risk Analysis .............................................. 32 
5.3.1 Parameters and Deterministic Benefit-Cost Analysis................................... 32

5.3.2 Standard Errors of Coal and Oil Prices........................................................ 36

5.3.3 NPV Simulation and Analysis .................................................................. 37

5.3.4 NPV Simulation and Analysis with EIA’s Data ............................................ 42

5.4 Feasibility Comparison with Other Liquid Fuel Mitigation Options............................ 46

5.5 Investment Returns Comparison with Other Industries................................................ 48

5.6 Breakeven Point for the West Virginia Coal Conversion Project................................. 48

Chapter Six - Summary and Conclusions ………………………………………………….... 51

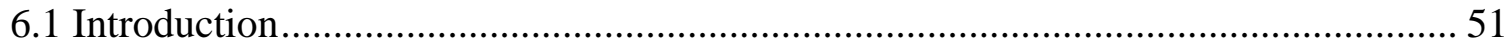

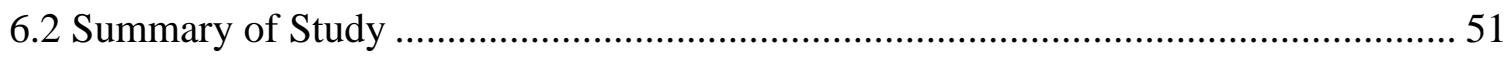

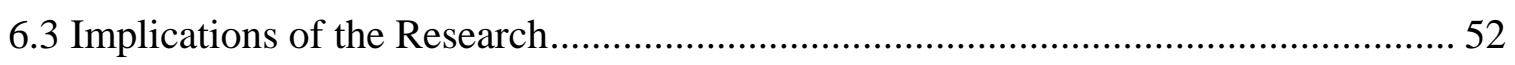

6.3 Limitations of the Study......................................................................................... 54

6.4 Directions for Future Research ………………………………………………... 54

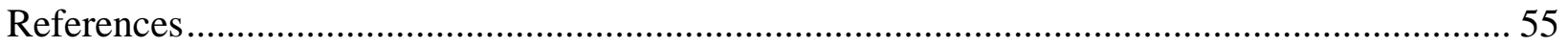

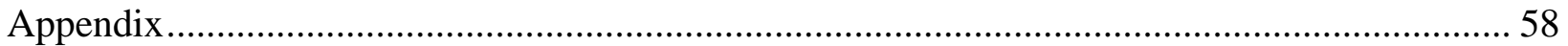




\section{List of Tables}

Table 2.1: Types of Direct Coal Liquefaction and Indirect Coal Liquefaction Technologies ....... 7

Table 4.1: Coal Liquefaction Plants Yield Data, Powhatan Coal Case ..................................... 23

Table 5.1: Granger Causality Test Results for Oil and Average Lignite Prices ......................... 30

Table 5.2: Granger Causality Test Results for Oil and Average Bituminous Prices ................... 30

Table 5.3: Granger Causality Test Results for Oil and Average Anthracite Prices.................... 30

Table 5.4: Granger Causality Test Results for Oil and Average Coal Prices ............................. 31

Table 5.5: Financial Statement Abstract of "West Virginia Coal Conversion Preliminary

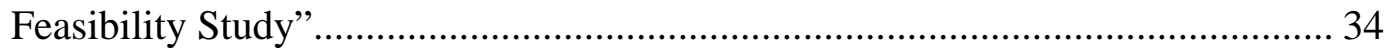

Table 5.6: Outputs Composition of WV Coal Conversion Project............................................. 36

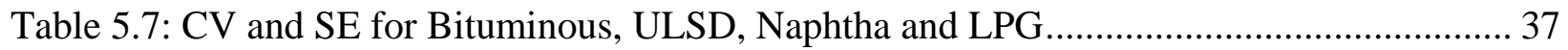

Table 5.8: Correlation Coefficient Matrix for LPG, Bituminous and Crude Oil........................ 37

Table 5.9 : CV and SE for Coal, ULSD, Naphtha and LPG Prices Based on EIA Data............. 42

Table 5.10: Industry Investment Returns and Standard Deviations ....................................... 49

Table A.1: The U.S. Nominal Coal Prices, 1949-2004. (Dollars per short ton)......................... 58

Table A.2: The U.S. Nominal Crude Oil Price, 1949-2004. (Dollars per barrel)....................... 60

Table A.3: The U.S. Nominal Natural Gas Price, 1949-2004. (Dollars per barrel) .................... 62

Table A.4: Cushing, OK WTI Spot Price FOB (Dollars per Barrel) ......................................... 64 


\section{List of Figures}

Figure 2.1: Major Inputs and Outputs of Fischer-Tropsch Indirect Coal Liquefaction................. 5

Figure 2.2: Petroleum Supply Structure Forecast of the U.S. in 2030...................................... 8

Figure 2.3: The U.S. Reserves/Production Ratio of Fossil Fuels ............................................. 9

Figure 5.1: NPV Simulation Result (without correlation) of West Virginia Coal Conversion

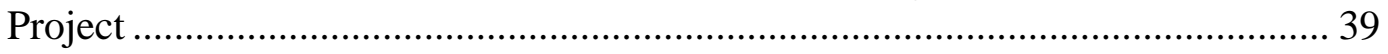

Figure 5.2: NPV Simulation Result (with correlation) of West Virginia Coal Conversion Project 40

Figure 5.3: NPV Simulation Result (without correlation) of West Virginia Coal Conversion

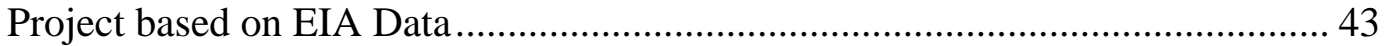

Figure 5.4: NPV Simulation Result (with correlation) of West Virginia Coal Conversion Project based on EIA Data ....................................................................................... 44

Figure 5.5: Cost Comparison of Different Types of Liquid Fuel Mitigation Options................ 47

Figure 5.6: Total Employment Impact per \$1 Million of Direct Cost ...................................... 47 


\section{Chapter One - Introduction}

\subsection{Problem Statement}

As oil prices continue to soar in the world market, coal liquefaction technology becomes an increasingly significant alternative for those countries that are rich in coal resources but poor in oil. However, there is no commercial scale coal-to-liquid (CTL) plant in the U.S. as of 2007. The large investment required and the associated risks are often cited as primary impediments to CTL development. The pressures of a skyrocketing oil price, environmental issues and energy security make today a better time than ever to evaluate the risk associated with developing a commercial scale coal to liquid plant.

Specifically, there are five primary types of risk: technical risk, market risk, environmental risk, commercialization risk and social risk. Since technical risk and environmental risk can be minimized with technical improvement and strict environmental regulations, market risk is thought the most important as it is related to many different inputs (primarily coal) and outputs (primarily oil) prices (National Mining Association, 2004). While oil products are not commonly considered downstream products of coal, the high degree of substitutability between coal and oil as sources of such products make oil price volatility the main source of market risk associated with coal liquefaction investments. Moreover, other risks associated with coal liquefaction development like environmental risk and commercialization risk are related to its market risk. Normally, large scale investors are considered risk averse and prefer a steady and stable rate of return. Therefore, the evaluation of market risk is the central issue in commercialization of coal liquefaction. 


\subsection{Objectives of the Study}

The overall goal of this study is to analyze the risk related to coal liquefaction projects in general and market risk in particular. Statistical and financial methods are used to evaluate the market risk associated with coal liquefaction projects. The following objectives must be met to meet the overall goal:

1. Identify the relationship between coal and oil prices,

2. Assess the market risk level associated with a specific coal to liquid project and

3. Discuss the implications of the research results.

\subsection{Methodology}

The methodology applied in this study involves the following steps:

1. Identify the sources of risks associated with coal liquefaction;

2. Examine the relationship among different sources of risk;

3. Estimate the risk level of a West Virginia coal conversion project using statistical, financial and computer simulation methods; and

4. Discuss the risk analysis results and explore the implications of the results for coal liquefaction risk management.

Time series techniques including the Granger Causality Test are used to examine relationships between input (coal) and output (oil products) prices. Given the high degree of substitutability between coal liquefaction and oil products, the price of oil is used as a proxy for output price. The Coefficient of Variation (CV) is calculated for input and outputs prices and used to forecast standard errors assuming that the CVs of the input and output prices are constant over time. Monte Carlo simulation is performed to assess the market risk of a coal liquefaction project in West Virginia.

\subsection{Outline for the Study}

The study is presented in six chapters starting with this introduction. Chapter two provides a background about coal liquefaction technologies and their significance and history. 
Chapter three is a review of relevant literature on risk analysis. Chapter four discusses the sources of coal liquefaction risks and strategies for coal liquefaction risk management. Chapter five presents a financial analysis and computer simulation of the West Virginia coal liquefaction project. Chapter six concludes this study with an extended discussion of the major results. 


\section{Chapter Two - Coal Liquefaction Fundamentals}

\subsection{Introduction}

Coal liquefaction techniques have been developed over more than one hundred years. This chapter provides a basic background about coal liquefaction's principles, significance and its development and history that help to understand the risk analysis presented in later chapters.

\subsection{Coal Liquefaction Technology}

Coal can be converted to liquid fuels either by removal of carbon or addition of hydrogen. The first approach is known as carbonization, and the second is known as liquefaction. The major objective of coal liquefaction is to produce synthetic oil to supplement the natural sources of petroleum. Liquid and solid products from coal can be used for fueling transportation vehicles, providing fuels for power generation, and yielding raw materials for chemicals.

Coal liquefaction can be accomplished through either direct or indirect processes. The two approaches are fundamental different. Indirect coal liquefaction processes first gasify the coal and then reconstitute the gasses produced into desired products, e.g., using a FischerTropsch process. Direct coal liquefaction involves making a partially refined synthetic crude oil from coal by adding additional hydrogen under high temperature and pressure conditions. It is widely believed that indirect liquefaction, while theoretically less efficient, is more cost effective than direct coal liquefaction techniques currently available (Williams, 2003). Overall thermal efficiencies (\% calorific value of the input fuel converted to finished products) for modern processes are generally in the $60-75 \%$ range if allowance is made for generating losses and other non-coal energy imports. Liquid fuels yield in excess of $70 \%$ by weight of the dry, mineral matter-free coal feed have been demonstrated in favorable circumstances (Kamall, 1999). Figure 2.1 shows the inputs and outputs of Fischer-Tropsch indirect coal liquefaction. 


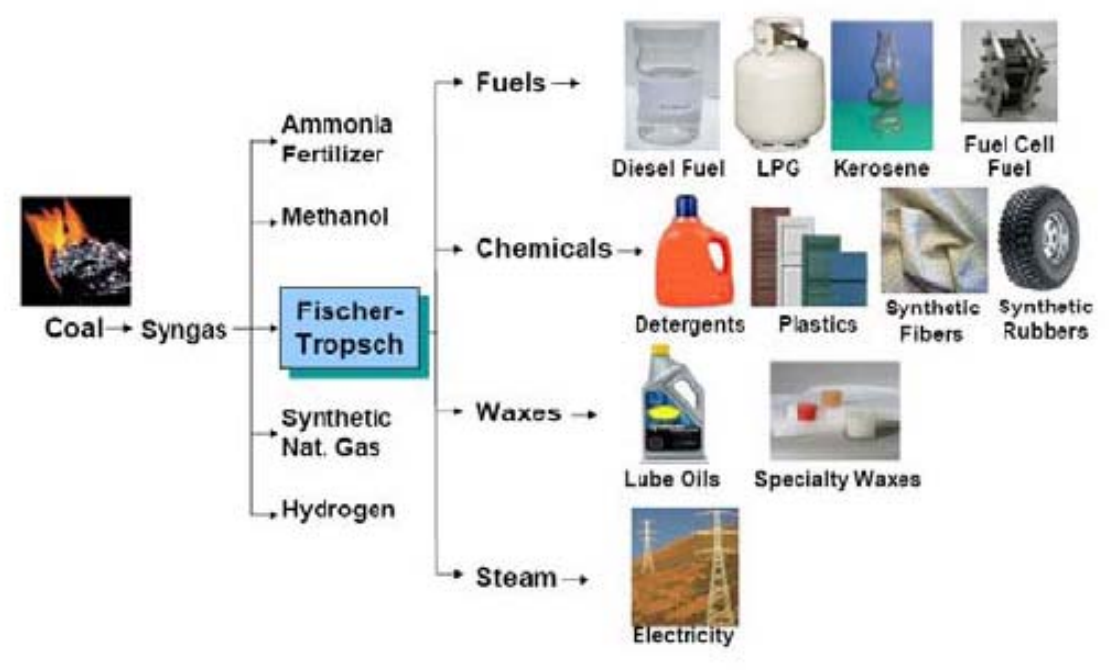

Figure 2.1: Major Inputs and Outputs of Fischer-Tropsch Indirect Coal Liquefaction (Source: “Liquid Fuels from U.S. Coal”, National Mining Association, 2004)

Direct liquefaction processes can be divided into two main groups by their specific processes: single-stage and two-stage, depending on whether the initial dissolution of the coal is separated from the conversion of the dissolved coal into distillable products (Mangold, et al. 1982). A single-stage direct liquefaction process produces distillates via one primary reactor or a train of reactors in series. An integrated hydro treating reactor may be included in such processes. A two-stage direct liquefaction process is designed to produce distillates via two reactors or reactor trains in series. The primary function of the first stage is coal dissolution and is operated either without a catalyst or with only a low-activity disposable catalyst. The heavy coal liquids produced in this way are hydro treated in the second stage with a high-activity catalyst to produce additional distillate.

Indirect liquefaction involves two steps. The first step is the complete breakdown of the coal structure by gasification. The composition of the gasification products is a mixture of $\mathrm{H}_{2}$ and CO referred to as syngas. Sulfur-containing compounds are also removed in this step. The 
resulting gasification products are reacted in the presence of a catalyst at relatively low pressure and temperature. The synthetic liquid products include paraffins, olefin hydrocarbons or alcohols (particularly methanol), depending on the catalyst selected and the reaction conditions used (Kamall, 1999).

The only large scale commercial operating process using indirect liquefaction of coal is South Africa's Sasol company with three operating plants. The core unit specific to indirect liquefaction is the synthesis reaction and the majority of recent research has therefore been concentrated on the development of improved catalysts, which need not be specific to a particular process (Kamall, 1999). Table 2.1 summarizes the types of coal liquefaction technologies and their developers.

\subsection{The Significance of Coal Liquefaction}

Without significant technological change energy growth will continue to be dominated by fossil fuels as indicated by trends in the emerging economies. Unfortunately, simply scaling up current energy technology to meet the needs of a fully developed world society of ten billion people is not a practical option (Lackner, 2004). Limits to consider include petroleum reserves, pollution created by these fuels and the greenhouse gas implications of the continued and unfettered use of fossil fuels.

Coal liquefaction can significantly improve U.S. national and economic security by lessening dependence on foreign oil and substituting plentiful, more affordable U.S. coal. Currently, about $56 \%$ of U.S. oil consumption relies on imports, and this figure is expected to increase in the next 20 years (EIA, 2006). Moreover, most U.S. oil imports are from the Middle East, where crude oil production and transportation are uncertain due to regional long-term instability. Coal liquefaction is a more secure way to produce liquid fuels that can help the U.S. 
decrease reliance on oil imports. It is uncontroversial that the U.S. and the world as well are facing the depletion of crude oil and that it takes time to replace traditional fossil fuels with renewable energy. According to a recent forecast by the EIA, liquid fuels from coal will account for about 3\% of the total U.S. supply of petroleum products by 2030 (EIA, 2006) (see figure 2.2).

Table 2.1: Types of Direct Coal Liquefaction and Indirect Coal Liquefaction Technologies

\begin{tabular}{|c|c|c|}
\hline \multirow{19}{*}{$\begin{array}{l}\text { Direct Coal } \\
\text { Liquefaction }\end{array}$} & \multirow{7}{*}{$\begin{array}{l}\text { Single- } \\
\text { stage }\end{array}$} & Kohleoel (Ruhrkohle, Germany) \\
\hline & & NEDOL (NEDO, Japan) \\
\hline & & H-Coal (HRI, USA) \\
\hline & & Exxon Donor Solvent (EDS) (Exxon, USA) \\
\hline & & SRC-I and II (Gulf Oil, USA) \\
\hline & & Imhausen high-pressure (Germany) \\
\hline & & Conoco zinc chloride (Conoco, USA) \\
\hline & \multirow{12}{*}{$\begin{array}{l}\text { Two- } \\
\text { stage }\end{array}$} & Catalytic Two-Stage Liquefaction (USDOE and HRI, now HTI, USA) \\
\hline & & Liquid Solvent Extraction (LSE) (British Coal Corporation, UK) \\
\hline & & Brown Coal Liquefaction (BCL) (NEDO, Japan) \\
\hline & & Consol Synthetic Fuel (CSF) (Consolidation Coal Co, USA) \\
\hline & & Lummus ITSL (Lummus Crest, USA) \\
\hline & & Chevron Coal Liquefaction (CCLP) (Chevron, USA) \\
\hline & & Kerr-McGee ITSL (Kerr-McGee, USA) \\
\hline & & Mitsubishi Solvolysis (Mitsubishi Heavy Industries, Japan) \\
\hline & & Pyrosol (Saarbergwerke, Germany) \\
\hline & & Amoco CC-TSL (Amoco, USA) \\
\hline & & Supercritical Gas Extraction (SGE) (British Coal Corporation, UK) \\
\hline & & Shenhua Process (Shenhua, China) \\
\hline \multirow{3}{*}{\multicolumn{2}{|c|}{$\begin{array}{l}\text { Indirect Coal } \\
\text { Liquefaction }\end{array}$}} & The Sasol Process (South Africa) \\
\hline & & The Mobil MTG Process (USA) \\
\hline & & The Shell SMDS Process (USA) \\
\hline
\end{tabular}

(Source: "Technology Status Report - Coal Liquefaction” - Cleaner Coal Technology Programme, Department of Trade and Industry, October 1999) 


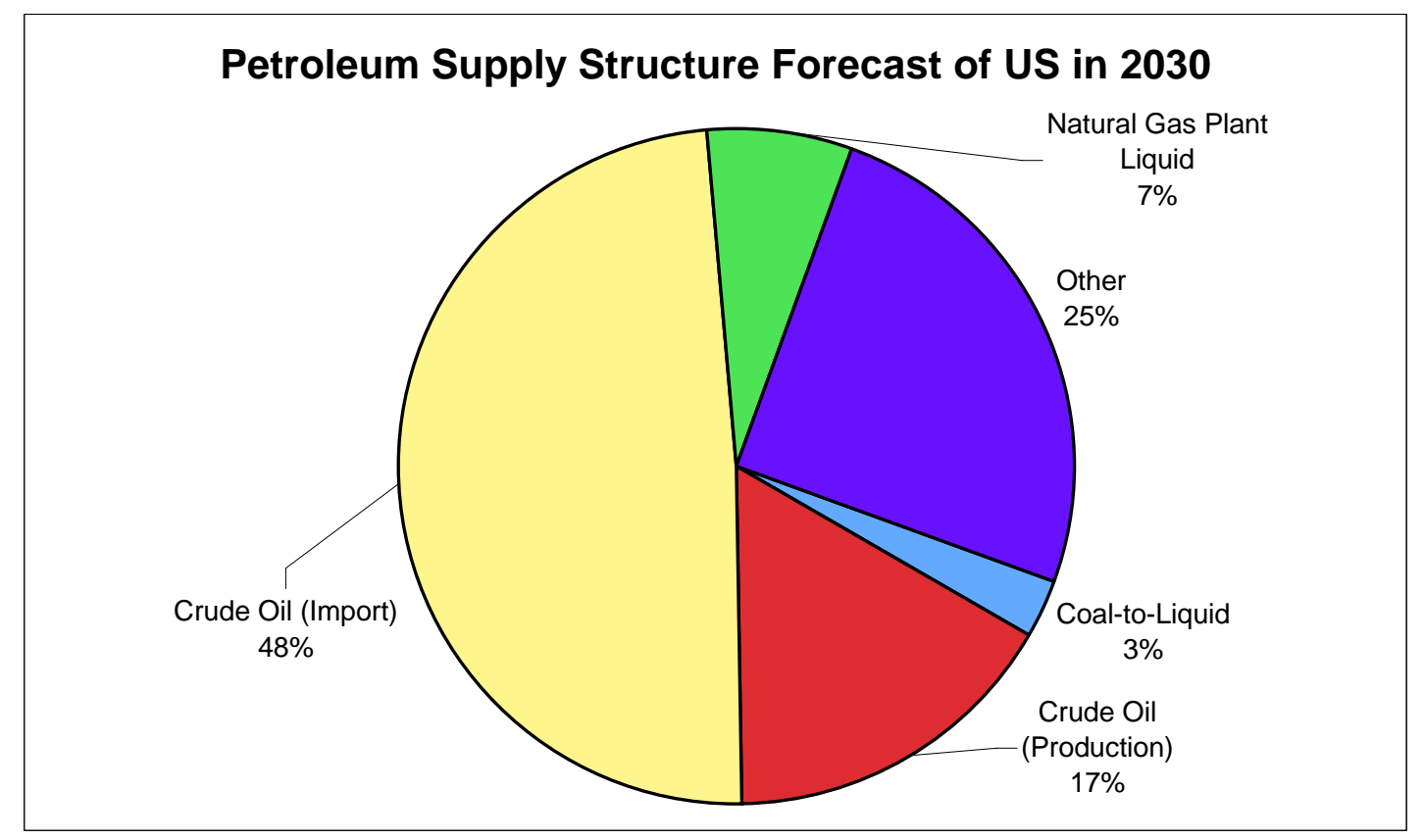

Figure 2.2: Petroleum Supply Structure Forecast of the U.S. in 2030

(Source: “Annual Energy Outlook 2006 with Projections to 2030”, EIA)

Coal liquefaction can also provide environmental benefits including cleaner fuels that reduce nitrogen oxide and particulate emissions and enable the use of higher efficiency engines. Conventional coal-fired power plants produce significant amounts of sulfur dioxide (SO2) as a result of burning coal. Coal liquefaction transfers the element sulfur contained in coal into a product and hence significantly reduces sulfur dioxide production. Thus both DCL and ICLderived fuels have air quality advantages over crude-oil-derived fuels: a low sulfur content that arises primarily as a result of process technology requirements. But aside from this common characteristic, emissions for DCL- and ICL-derived fuels often differ markedly (Williams and Larson, 2003).

Coal liquefaction technologies are also capable of capturing carbon dioxide $\left(\mathrm{CO}_{2}\right)$ emissions and serving as a bridge to a hydrogen fuel future through polygeneration, i.e., linking 
multiple types of plants into one, such as co-production of liquid fuels, electricity, hydrogen, etc., embodied in the FutureGen initiative (National Mining Association, 2004).

The U.S. is rich in coal reserves while poor in crude oil and natural gas. The BP Annual Statistical Review of Energy (2005) points out that the U.S. reserves-production-ratio of coal is more than 250 years, while this ratio is only about 11 years for oil and 9.8 years for gas (see figure 2.3). Therefore, coal liquefaction provides an alternative way to produce liquid fuel. Proven coal reserves are found in 38 states and all major regions of the U.S. Commercial coal liquefaction plants could provide geographic diversity in domestic refining capacity. A large coal liquefaction plant would have a positive impact on a regional economy. From a macroeconomic perspective, the commercial-scale application of coal liquefaction could lower U.S. reliance on crude oil imports and, thus, provide a positive influence on the U.S. balance of international trade.

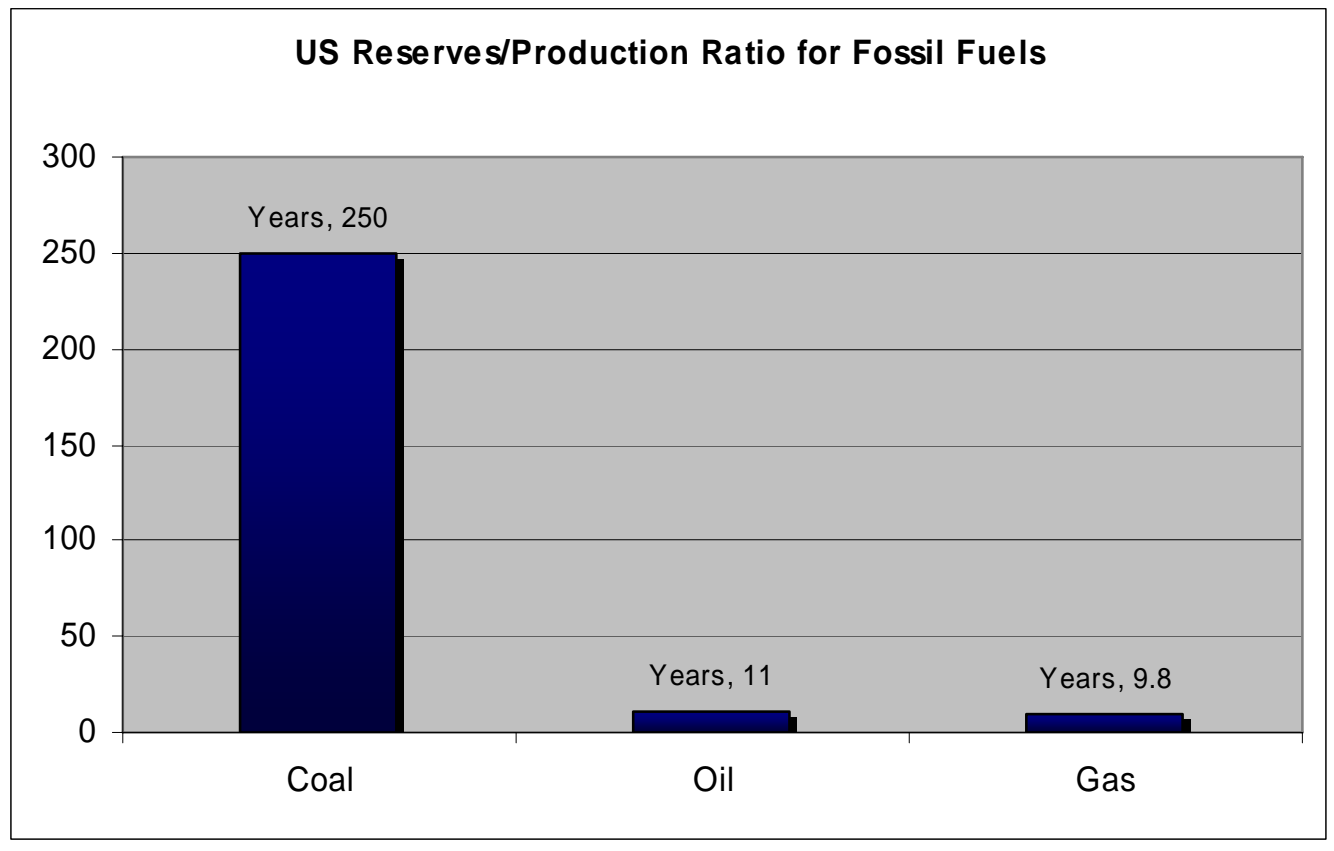

Figure 2.3: The U.S. Reserves/Production Ratio of Fossil Fuels (Source: EIA, BP Statistical Review of Energy, 2005) 


\subsection{The History of Coal Liquefaction}

Coal-derived liquids first developed as by-products of coke-making in Germany and the UK in the 1840s (Davis, 1997). These liquids had a variety of uses including solvents, wood preservatives and fuels, and, beginning in the 1850s, were used as the basis of the coal tar dyes. The first coal direct liquefaction process, designed by Bergius in 1913 and commercialized in the early 1920s, is known as either the Pott-Broche or I G Farben process (Lackner, 2004). The first indirect coal liquefaction process developed in 1925 represents a milestone in coal liquefaction history. Franz Fischer and Hans Tropsch invented a catalyst that could convert $\mathrm{CO}$ and $\mathrm{H}_{2}$ at 1 atm and 250 to 300C into liquid hydrocarbons. By 1941, Fischer-Tropsch plants produced 740,000 tons of petroleum products per year in Germany (Lackner, 2004).

At the start of the Second World War, both Germany and the UK had operational coal liquefaction plants. In 1935, a commercial-scale direct liquefaction plant processing coal and creosote oil to produce a total of 150,000 tons/year of gasoline came into operation at Billingham in the UK (Lackner, 2004). In Germany, 12 Bergius plants with a total capacity of about 70,000 barrels of liquid fuels per day produced aviation gasoline from lignite, tar, and hard coal; nine Fischer-Tropsch plants with a total capacity of 15,000 barrels per day produced transport fuels and chemicals. Fuels from these coal liquefaction plants accounted for $90 \%$ of German consumption during the Second World War (IEA, 1982).

Following the war coal liquefaction plants in Germany and elsewhere were generally closed down. In 1954, the discovery of huge reserves of crude oil and natural gas in the Middle East resulted in declining interest in coal liquefaction technologies. As the cost of converting coal into liquid fuels was much higher than that of producing fuels form crude oil, attention and efforts switched from developing coal liquefaction to the discovery and use of crude oil. The oil 
crisis of the early 1970s led to significant renewed interest in coal liquefaction research and development (R\&D) focusing on variants of direct liquefaction. The main participants were the U.S., Japan, UK, and Germany (Kimber, 2000). Coal liquefaction, via indirect processes, attracted less interest, although there were parallel developments in synthesis reaction catalysis and technology for other purposes. Almost all of the current liquefaction processes originated during this period.

South Africa was a special case. Because of its apartheid policies, South Africa became increasingly politically and economically isolated from the mid-1950s to the mid-1980s. With no indigenous oil and unable to trade freely in oil and oil products but with large coal reserves, South Africa relied heavily on coal liquefaction to meet its need for liquid fuels. Indirect liquefaction was selected as it was thought better suited to South African coals. The first plant was built by Sasol in the 1950s. Two additional indirect liquefaction plants built in 1980 and 1982 applied improved catalyst formulations and reactor designs. In the mid-1980s these plants produced up to 10 million tons/year of transportation fuels, about $60 \%$ of South Africa's requirements (Davis, 1997).

However, most research and development activities focused on direct rather than indirect coal liquefaction during this period largely because the efficiency of the direct process was believed to be higher than that of the indirect process, i.e., the Fischer-Tropsch process (IEA, 1982). With lower oil prices in the 1980s, interest in coal liquefaction for the production of transportation fuels declined. From 1985 to 1990s, only Japan kept large-scale process development active with a 150 tones/day plant in operation. The U.S. successfully developed liquefaction technologies, but treated them as a strategic technology only. Stepping into the 21st 
century, the energy crisis resurfaced. As the price of oil continued to increase, many countries, including China, the U.S. and India, begin to pick up this technology again. 


\section{Chapter Three - Literature Review}

\subsection{Introduction}

Risk analysis is a classical way to deal with uncertainties in financial, environmental and technical fields. This chapter presents an overview of the literature on risks associated with coal liquefaction, reviews the literature on risk analysis procedures, and introduces some useful tools for coal liquefaction risk analysis.

\subsection{Risks Associated with Coal Liquefaction}

Omole, Borisade and Muhannad (2004) divided risks related to the oil and gas industry into four categories: technical, environmental, financial (or market) and political. Technical risk relates to whether the hydrocarbon volumes estimated by the geologist and engineers exist in the ground and whether the reserves and recovery rates will be as projected. Technical uncertainty is always a function of how long the property has produced, its maturity and the quality of the data from which the reserves' estimates were calculated. Environmental risk relates to the need to ensure the safety of life, the health of personnel, the reduction of environmental pollution and the safeguarding of investment. Market risk refers to the risk that product prices, operating costs, inflation and market conditions will be in reasonable agreement with the assumptions used in the financial analysis of the project at the planning stage. Political risk involves the uncertainty arising from possible changes in the policies of regulatory bodies and the degree to which such changes may affect the project cost and revenue.

Environmental risk analysis is a fast-developing field. Suter et al. (1986) define environmental risk analysis as the process of identifying and quantifying probabilities of adverse changes in the environment resulting from human activities. In their study, 38 potentially significant contaminants were listed, including carbon monoxide, sulfur oxide and nitrogen 
oxide; and five ecological end points used: reduction in fish populations, development of algal populations that detract from water use, reduction in timber yield or undesirable changes in forest composition, reductions in agricultural production and reductions in wildlife populations. The study also analyzed risks associated with two oil shale technologies: TOSCO II and Paraho. The analysis assumed commercial-scale facilities with identical feed shale capacities and similar environmental control technologies. The methodology used in this study is relevant to coal liquefaction where the market risk and environmental risk can be identified first and then specific technologies can be assumed for commercial-scale simulation. Suter applied two oil shale technologies for his study’s risk analysis, while in this study, GSP Rench, a specific coal liquefaction technology, is used to assess the market risk associated with coal liquefaction.

Micallef (1981) focused on the assessment of political risk. He attributed political risk to the expectation of political policies. The more accurate the expectation is, the lower political risk is. He also recommended three methods to analyze political risk: identify the elements of political risk associated with foreign direct investment and develop a system to monitor and evaluate political changes; take political risk into account when planning a project; diversify a project's investment so that risk can be diversified as well.

The implications of these studies are significant for the analysis of coal liquefaction risk. Coal liquefaction projects are highly risky as there are many different kinds of uncertainties involved. Omole, Borisade and Muhannad provided a scientific way to classify these uncertainties that can be applied in studies on coal liquefaction risk. The difference is coal liquefaction plants are usually supported by the government and so far there's no foreign investment involved in these projects. Therefore, their political risk could be low and the focus of coal liquefaction risk analysis can be placed on market, environmental and technical risk. 


\subsection{Risk Analysis Methods}

There are many studies of risk analysis methods. Hartz (1964) demonstrated how various techniques could be applied and how they could have a great impact on decision makers. He thought methods that combined both statistical and financial analysis would be more interpreted especially for market risk analysis. Hamdhi (1996) discussed ways to minimize the negative economic impact of volatile oil prices on a project and to optimize the use of resources if oil price is not stable. He also concluded four major aspects that might bring risk: reduction in investment, environmental issues, policies and workforce optimization. From the financial perspective, capital chain and ample budget are the most vital factors that can keep a risky project in the long run. Environmental issues and policy changes, to some extent, would bring in the extra financial cost and raise the external cost. Workforce optimization is another way to stabilize production efficiency and therefore, minimize the uncertainty that may occur at the production process. Torries (1998) stated that, "Probabilistic can be thought of as the ultimate form of scenario analysis in that all possible cases are considered simultaneously”. He recommended Monte Carlo simulation for financial forecasts and analysis and showed the simulation could provide a clear insight of different economic cases. Hammonds, Hoffman and Bartell (1994) laid down guidelines for evaluating uncertainty in mathematical equations and computer models applied to assess human health and environmental risk. Analytical and numerical methods for error propagation are presented along with methods for identifying the most important contributors to uncertainty. Monte Carlo simulation with either Simple Random Sampling (SRS) or Latin Hypercube Sampling (LHS) is proposed as the most robust method for assessing uncertainty in either simple or complex models. 
Pouliquen (1970) introduced a classical method of risk analysis which permits the use of a great deal of information and enables researchers to handle uncertainty, not only about the viability of a marginal acceptable project but also about the most appropriate design, phase or size of a clearly acceptable project. He pointed out that the entire framework of risk analysis provides a highly efficient medium of communication and a focus for evaluation and discussion. Risk analysis is in no sense a technique that replaces skilled judgment. On the contrary, it often requires the use of far more judgment than traditional analysis.

Rodger and Petch (1999) argue that the classical phases of risk analysis can be divided into five stages: identifying the risks, quantifying the risks, risk analysis, presenting the results and beyond presentation. They suggest that from initial workshops into preliminary qualification and then preliminary modeling, researchers should focus on significant risks (such as market risk and environmental risk for coal liquefaction). When it comes to detailed workshops and interviews, further risk models can be built up on the base of preliminary models, but researchers need to go back to detailed workshops frequently so that the risk model is more likely to be precise.

Risks can have both positive and negative outcomes and can occur in any domain of a company’s operations, from engineering to finance. According to Kleindorfer (2000), risk analysis in industrial contexts consists of four integrated processes: (i) identifying underlying sources of risk, (ii) determining the pathways by which such risks can materialize, (iii) estimating the potential consequences of these risks under various scenarios, and (iv) providing the means for mitigating and coping with these consequences. Kleindoefer paid more attention to finding out the source of risks and to reducing risks from their sources. He suggested such a process could be well applied in assessing risks related to ecology systems and environmental 
issues. This risk analysis procedure is also useful for environmental and market risk analysis of coal liquefaction since these two kinds of risks are the main sources of all other risks.

Friedman (1997) put forward a conceptual structure widely used in risk management.

This structure includes the following activities:

(i) Hazard Identification: list materials, processes and products of potential concern and qualitatively prioritize these by their relative hazard;

(ii) Risk Assessment: determine the credible releases, exposure pathways and events that might result from various events and scenarios and calculate the median and worst case hazard zones associated with these;

(iii)Risk Analysis: consider all safety systems, redundancies and mitigation possibilities, calculate detailed probability distributions for the hazards identified, and consider damage reduction possibilities;

(iv)Risk Management: specify risk acceptance and risk reduction guidelines, specify process hazards management procedures, including emergency response procedures, structure financial and insurance provisions, and establish communication procedures with affected employees and the public.

Friedman's framework for risk analysis is a systematic and useful approach to risk

analysis. He suggested that the definition of risk should be associated with hazard identification which can narrow down the general risks for a specific project. A limitation of this approach is that it has very demanding data requirements.

\subsection{Tools for Risk Analysis}

Typically, methods to incorporate risk into project analysis include Net Present Value (NPV) calculations, sensitivity analysis, scenario analysis, probabilistic analysis, Monte Carlo simulation, certainty equivalence, Bayesian methods and political risk assessment (Torries, 1998). Among these methods, NPV is the most popular for market risk analysis as it is easy to calculate with an adjusted risk discount rate. However, the use of NPV has its own disadvantages and limitations. Myers (1976) pointed out a major limitation of the NPV method as follows, "If NPV is calculated using an appropriate risk adjusted discount, any further adjustment for risk is double-counting. If a risk-free rate of interest is used instead, then one obtains a distribution of 
what the project's value would be tomorrow as if all uncertainty about the project's cash flows were resolved between today and tomorrow. But since uncertainty is not resolved in this way, the meaning of the distribution is unclear."

Risk analyses based on Monte Carlo simulation can be useful if it is meaningful to attach distributions to the variables entering the cost benefit analysis. Simulations depict the distribution of the net present value. Confidence intervals of the expected net present value can be obtained and the probability that the project has a positive net present value can be estimated.

Another risk analysis tool is VAR (Value-at-Risk), which is becoming increasingly popular in market risk analysis (Manfredo, 1998). Not all cases are suitable for the VAR approach. Manfredo and Leuthold (1998) pointed out that the use of agricultural prices can bring new data to the empirical evaluation of Value-at-Risk. The performance of VAR techniques when applied to agricultural product prices might be quite different from that applied to financial asset prices.

Although risk analysis has long been a useful tool, there are few papers published with a primary focus on the risk analysis of coal liquefaction. The studies discussed above provide a good understanding of the concept and method of risk analysis. No doubt, those concepts and methods can be applied to the risk analysis of coal liquefaction projects. Risks associated with coal liquefaction are quite diversified. In addition to market risk, technical risk and environmental risk also critically affect project feasibility. Moreover, these risks interact, further increasing the difficulty of risk analysis. For instance, the improvement in coal liquefaction technology may not only reduce market risk but also environmental risk. Thus, in coal liquefaction risk analysis, it is important to understand the relationships among the various sources and types of risk. For a commercial scale CTL (Coal-to-Liquid) plant, market risk is the 
most important and has prevented many potential investments. The risk of coal liquefaction comes mainly from market risk, and NPV is still widely believed to provide a useful way to analyze market risk. 


\section{Chapter Four - Risk Associated with Coal Liquefaction}

\subsection{Introduction}

This chapter introduces and analyzes five types of risks associated with coal liquefaction: technical, market, environmental, commercialization and social risk. For each type of risk, potential risk management strategies are discussed and recommended.

\subsection{Technical Risk}

There are technical uncertainties throughout the coal liquefaction process. From a technical perspective, integrated operations of advanced coal liquefaction technologies have never been demonstrated. For instance, are synthetic liquid fuels perfect substitutes for traditional gasoline and diesel? What is the conversion efficiency? After more than one hundred years of development, the main technical risk of coal liquefaction today is related to coal-toliquid conversion efficiency (Williams and Larson, 2003). In other words, the uncertainty with respect to how much raw coal can be transformed into liquid fuel is the issue that has the greatest impact on the economics of the project. Researchers have long argued about coal liquefaction conversion efficiency. Williams and Larson (2003) think that even though the theoretical conversion efficiency varies between direct and indirect processes, there is no significant difference in effective conversion efficiency between the two technologies. The reason for the difference is that DCL efficiencies are for partially refined products while ICL efficiencies are for final products (Williams and Larson, 2003). The overall conversion efficiency of coal-toliquid technologies is about 60 70 percent (Kamall, 1999). That is, about 60-70 percent or even higher of the thermal energy goes into liquid fuels.

Technical risk can be reduced by constructing pioneer commercial scale coal liquefaction plants. A pioneer plant is a stand-alone facility, with the function of demonstrating that continued 
operation of coal liquefaction is technically and financially feasible. Since there is only one commercial scale coal liquefaction technology in operation in the world today, Sasol's synthetic fuels plants in South Africa, pioneer coal liquefaction plants can test the technical risk of alternative technologies with a lower investment. A pioneer commercial scale plant can be onequarter of full size (IEA, 1982). Once a technology has proven successful in pioneer commercial scale plants, large coal liquefaction plants can be constructed at lower technical risk.

\subsection{Market risk}

Market risk associated with coal liquefaction includes the uncertainty of world oil prices, plant operation costs, initial capital investment, and inflation rate and so on. Market risk of coal liquefaction refers to the price fluctuation of a project's inputs and/or outputs that affect the profitability of the project. Traditionally, liquid fuels are not the downstream products of the coal industry. Therefore, a rise in coal prices does not necessarily lead to a rise in the price of coal liquefaction products. Historically, coal prices are more stable than oil prices which are usually affected by a number of economic and noneconomic factors such as wars, political turmoil and direct OPEC manipulations. From January 05, 2004 to August 30, 2005, Cushing, OK WTI Spot Price FOB (Dollars per Barrel) varied between $\$ 33.71 /$ bbl and \$69.91/bbl (EIA, 2006) (table A4). This indicates that fluctuating oil prices account for a significant component of market risk. The second component of market risk related to coal liquefaction is high initial capital cost. A 50,000-bbl per day HCoal commercial plant’s capital requirement is about $\$ 1$ billion at 1978 dollars (Mangold, 1982). Among all the risks associated with coal liquefaction, market risk is the most significant. In contrast, it is relatively easier to deal with other risks as the technology matures. Unfortunately, the market risk associated with the development of a coal liquefaction sector remains an obstacle that limits potential investors in this field. 
According to the National Mining Association (2004), financial uncertainty is the primary reason that commercial-scale coal liquefaction plants in the U.S. have not yet been developed. The National Mining Association's publication (2004) concludes: “One reason is the historic sharp volatility of oil prices - if the price of oil stays above \$35 per barrel, a coal refinery makes economic sense. If it drops below that figure, as it has in the past, there is no assurance a coal refinery can remain competitive, posing a substantial risk for investors. Secondly, the front end cost is high - coal refineries are expensive to construct, with capital costs in the \$600-million-to-\$700-million range for a 10,000 barrel per day plant, according to FT Solutions LLC. The technical and market risks of a 'first of a kind' plant in the United States have discouraged consideration of this type of investment in the past. Finally, the lead time for a coal refinery plant in the U.S., as with all refineries, is a minimum of five to seven years under optimal circumstances.”

As the two most important sources of fossil energy, coal and oil can substitute for each other given the similarity in chemical composition. Due to the substitutability between oil and coal, when oil prices are high, coal may be used to replace oil, hence the demand for coal will increase which results in a higher coal price. The relationship between coal and oil prices is relevant to the study of the market risk associated with coal liquefaction because coal is the input while substitutes for oil products are the output. If coal and oil prices have a positive correlation, the market risk of coal liquefaction is lowered. Also, the higher oil prices are, the less risky a coal liquefaction project would be. The average retail gasoline price in US has been more than doubled over the past 2 years. As of mid 2007, the international crude oil price is fluctuating around $\$ 70 /$ bbl and seems unlikely to drop significantly in the near future. EIA (2006) forecasts that the average price for petroleum products in the U.S. will increase from the current $\$ 12.61$ 
per million Btu to $\$ 15.16$ per million Btu by 2030, an annual growth of $0.7 \%$, while the average coal price will increase from $\$ 1.35$ per million Btu to $\$ 1.53$ per million Btu over the same time period, an annual growth of $0.4 \%$. These forecasts indicate that the price difference between coal and oil will remain high and may even increase in the next 25 years. For coal liquefaction investments, this means a decrease in market risk.

\subsection{Environmental Risk}

Even though coal liquefaction is a clean coal use, it may still have a significantly negative impact on the environment (Fletcher et al., 2004). The commercialization of coal liquefaction, an expansion of coal use, would inevitably result in more environmental pollution. Table 4.1 is the yield data of Powhatan Coal Liquefaction Case, which is scientifically designed to maximally lower the pollutant emission. This case shows that $\mathrm{CO} 2, \mathrm{H} 2 \mathrm{~S}$ and ash are the primary pollution source from coal liquefaction. Specifically, such expansion of coal use would bring potential damage to human health, air, water and soil quality, agriculture and the local ecology. Atmospheric emissions may include carbon oxides, sulfur oxides, nitrogen oxides and particulates from heaters that burn fossil fuels. Through a coal liquefaction process, not all coal is directly used to produce liquid fuels. Instead, some of the coal may be burned to generate energy that is needed for the liquefaction process, though some plants can use some of the final products once the plant is running. Atmospheric emissions can be in forms of fuel gas, liquid hydrocarbon fuel oils or raw coal burned to produce electric power and steam.

Table 4.1: Coal Liquefaction Plants Yield Data, Powhatan Coal Case

\begin{tabular}{|l|l|}
\hline Component & Yield (wr \%) \\
\hline $\mathrm{C}_{1}$ & \\
\hline $\mathrm{C}_{2}$ & 4.4 \\
\hline $\mathrm{C}_{3}$ & 4.1 \\
\hline $\mathrm{C}_{4}$ & 2.2 \\
\hline
\end{tabular}




\begin{tabular}{|l|l|}
\hline $\mathrm{C} 5-350^{\circ} \mathrm{F}$ & 7.9 \\
\hline $350-600^{\circ} \mathrm{F}$ & 20.1 \\
\hline $600-900^{\circ} \mathrm{F}$ & 8.0 \\
\hline $900^{\circ} \mathrm{F}+$ & 24.0 \\
\hline Undissolved Coal (IOM)d & 4.62 \\
\hline $\mathrm{H}_{2} \mathrm{O}$ & 6.2 \\
\hline $\mathrm{H}_{2} \mathrm{~S}$ & 2.45 \\
\hline $\mathrm{NH}_{3}$ & 0.45 \\
\hline $\mathrm{CO}$ & 0.08 \\
\hline $\mathrm{CO}_{2}$ & 1.0 \\
\hline $\mathrm{HCl}$ & 0.02 \\
\hline Ash & 12.0 \\
\hline Residual S+Cl & 1.08 \\
\hline Total & 104.40 \\
\hline
\end{tabular}

Source: Phase Zero Conceptual Plant Design, 1979)

Technically, about 60 70 percent or even higher of carbon molecules will exist in liquid fuels and other chemicals products, while the rest would be emitted as carbon dioxide and other types of pollutants. Since a coal liquefaction process does not burn the coal, the sulfur content in coal can turn into sulfur products rather than sulfur dioxide. Besides atmospheric pollution, numerous wastewater streams may be generated from steps in the process of coal liquefaction. Representative contaminants include sour water containing oils, phenols, NH3, H2S, CO2, SO2, HCN, NOX and spent solvents (Mangold, 1982). A coal liquefaction facility produces a large volume of solid wastes as well. Since high-ash coals are prime candidates for conversion, $15 \sim 20 \%$ of the raw coal may consist of inert material requiring environmentally acceptable disposal by land filling (Mangold, 1982).

Managing the environmental risk of coal liquefaction is a challenging task. We used to believe it was difficult to measure and quantify the precise risk level associated with toxic chemicals. To completely understand the environmental risks involved in the coal liquefaction process, case-specific environmental risk assessment is required. Coal liquefaction plants can 
employ commercial treatment processes, such as Benfield, Purisol, Rectisol, Selexol or Sulfinol to remove atmospheric pollutants (Mangold, 1982).

However, the environmental risk may be solved through technology development. The current coal-to-liquid plant under development by the Shenhua Group in China has a "zero emissions" goal that would eliminate all environmental pollution, both air and water. The waste water can be recycled and carbon dioxide can be stored underground. Although the zero emissions goal has not yet been demonstrated, research on carbon sequestration and coal mining can help to reduce environmental risk. Careful siting of coal liquefaction plants can also minimize environmental risks. Field sampling and testing should be done periodically, so that the emissions of pollutants can be monitored and recorded.

\subsection{Commercialization and Operating Risk}

Because of the complexity of the coal-to-liquid (CTL) processes and the high cost, after one hundred years of development, there is not a mature CTL technology in the U.S. (National Mining Association, 2004). While the U.S. developed CTL technologies after the Second World War, these techn0ologies have not been tested or applied commercially. Germany operated nine indirect CTL (ICL) and 18 direct CTL (DCL) plants to produce liquid fuels during the Second World War. The commercial viability of coal liquefaction depends on the overall economics of the process, that is, the availability of significant quantities of low cost coal and relatively high prices of oil and natural gas products.

It appears that there is significant competition for CTL commercialization. Many countries, including the U.S., China and Japan, are interested in developing commercial scale coal liquefaction plants. As noted earlier, the only existing commercial scale coal liquefaction plants are located in South Africa using the Sasol indirect coal liquefaction technology. China is 
constructing two ICL plants and one DCL plant, the first commercial DCL plant since World War II and by far the largest ever attempted. Competition for critical process equipment and engineering skills drive up costs and make the investment even more risky. As the initial capital and operating costs for CTL plants are extremely high and many uncertainties are involved in commercial operation, governmental support is an important component of successful CTL commercialization. Clearly, companies and countries with abundant capital resources and mature technologies would take the lead in the CTL commercialization competition.

Another potential risk is operating risk. Coal liquefaction processes react at high temperature and pressure. Operating errors may result in explosions and injuries. Large amounts of hydrogen and carbon monoxide are needed for chemical reactions, both are explosive. However, this type of risk can be lowered if operators are proficient and well trained and appropriate monitoring systems utilized.

\subsection{Social Risk}

The development of a coal liquefaction sector creates jobs in local areas but produces environmental problems related to coal mining and utilization. Therefore, construction of CTL plants may be opposed by local residents and environmentalists. Ideally, CTL plants should be located close to large coal reserves and in areas with a low population density. The construction of commercial scale CTL plants can lead to the local growth or even the establishment of new communities, generating significant positive impact on regional economy. Public awareness of the significance of CTL is important to gain the support of local residents and reduce social risk. 


\section{Chapter Five - West Virginia Coal Conversion Project Risk Analysis}

\subsection{Introduction}

This chapter focuses on market risk analysis of a proposed West Virginia coal liquefaction project using statistical and financial analysis methods. First, the Granger Causality Test is applied to identify statistical relationships between coal and oil prices. By doing so, we can better understand of the interrelationship between the two most important variables that affect the market risk associated with the coal liquefaction project. Second, the coefficient of variation (CV) is calculated for input and output prices to estimate the standard errors, which are used to represent the financial uncertainties of the proposed coal liquefaction project. Third, Monte Carlo simulations are performed to obtain the net present value (NPV) of the proposed coal liquefaction project under alternative assumptions with respect to the relationship between oil and coal prices to analyze the market risk. A detailed discussion is provided based on the simulation results.

\subsection{The Relationship between Coal and Oil Prices}

Yoshimitsu (2000) studied the relationship between coal and oil prices and found that coal prices were not linked to the oil price based on the historical prices of coal, oil and natural gas in the Japanese domestic market from 1965 through 2002. His study showed the price of coal in Japan was higher than that of crude oil and liquefied natural gas (LNG) before 1973. The LNG price is closely linked to the price of crude oil, while the linkage between coal and oil prices has not been verified since 1986. After the 1973 Oil Crisis, the prices of crude oil and LNG significant exceeded coal prices and became more volatile. Moreover, despite a rapid rise in 
crude oil prices since the spring of 1999, the coal price continued to fall and finally reached a fairly low and stable level from 1999 through 2001 (Yoshimitsu, 2000).

Yoshimitsu's finding reflect the Japanese energy market. As is known, Japan has very low fossil fuels reserves and relies on imports to meet domestic oil and coal consumption needs. Hence, the domestic price in Japan is driven almost entirely by its international strategy and world market prices. However, the situation is quite different in the U.S. Although $56 \%$ of the U.S. crude oil consumption is imported (EIA, 2004), the U.S. has large amounts of coal reserves and coal prices are much more stable than in the world market. An understanding of the correlation between coal price and oil price is necessary to estimate the market risk associated with the coal liquefaction project.

In this section, the Granger Causality Test is used to test whether coal prices indeed affect oil prices or vice versa. The Granger Causality Test is a statistical method to examine the nature of causality between different variables (Gujarati, 2003). As the relationship between coal and oil prices is difficult to tell, the Granger Causality Test can help to understand their influences on each other. Annual data used for Granger Causality Tests include the annual average crude oil prices, the annual average coal prices, the annual average lignite prices and the average bituminous prices in the U.S. from 1949 to 2004 (EIA) (Appendix Tables A-1 and A-2).

The test involves estimating the following pair of regressions:

$$
\begin{aligned}
& P_{\text {coal }, t}=\sum_{i=1}^{n} \alpha_{i} P_{\text {oil }, t-i}+\sum_{j=1}^{n} \beta_{j} P_{\text {coal }, t-j}+u_{1 t} \\
& H_{0}: \sum \alpha_{i}=0
\end{aligned}
$$




$$
\begin{aligned}
& P_{o i l, t}=\sum_{i=1}^{n} \lambda_{i} P_{o i l, t-i}+\sum_{j=1}^{n} \delta_{j} P_{\text {coal }, t-j}+u_{2 t} \\
& H_{0}: \sum \delta_{j}=0
\end{aligned}
$$

Equation 5.1 postulates that the current coal price is related to past values of itself as well as those of oil, and Equation 5.2 postulate a similar behavior for oil prices. The null hypothesis for Equation 5.1 states that the terms of lagged oil prices do not belong in the first regression, while the null hypothesis for Equation 5.2 states that lagged coal prices do not belong in the second regression. Annual data are used in these tests. To test whether oil prices cause the coal price, first regress current coal prices on lagged coal prices and lagged oil prices. From this regression obtain the restricted residual sum of squares, $R S S_{R}$. Second, run the regressions including the lagged oil prices. From this regression obtain the unrestricted residual sum of squares, $R S S_{U R}$. The null hypothesis is $H_{0}: \sum \alpha_{i}=0$, that is, lagged oil prices do not belong in the regression. To test this hypothesis, we apply the F test given by $F=\frac{\left(R S S_{R}-R S S_{U R}\right) / m}{R S S_{U R} /(n-k)}$ which follows the F distribution with $\mathrm{m}$ and (n-k) df; $\mathrm{m}$ is equal to the number of lagged oil prices terms and $\mathrm{k}$ is the number of parameters estimated in the unrestricted regression. If the computed $F$ value exceeds the critical $F$ value at the chosen level of significance, we reject the null hypothesis, which means oil prices cause coal prices. The above steps can be repeated to test whether coal prices cause oil prices. The resulting F values and the results of these Granger Causality Test results are shown in tables 5.1-5.4. 
Table 5.1: Granger Causality Test Results for Oil and Average Lignite Prices

\begin{tabular}{|l|l|l|l|}
\hline Direction of causality & Number of lags & F values & Decision (Ho: No causality) \\
\hline Oil $\rightarrow$ Lignite & 1 & 14.6857 & Reject at $1 \%$ \\
\hline Lignite $\rightarrow$ Oil & 1 & 2.2139 & Do not reject \\
\hline Oil $\rightarrow$ Lignite & 2 & 3.9919 & Reject at $5 \%$ \\
\hline Lignite $\rightarrow$ Oil & 2 & 2.5849 & Reject at $10 \%$ \\
\hline Oil $\rightarrow$ Lignite & 3 & 2.7210 & Reject at $10 \%$ \\
\hline Lignite $\rightarrow$ Oil & 3 & 1.3759 & Do not reject \\
\hline Oil $\rightarrow$ Lignite & 4 & 1.9512 & Do not reject \\
\hline Lignite $\rightarrow$ Oil & 4 & 2.4660 & Reject at $10 \%$ \\
\hline Oil $\rightarrow$ Lignite & 5 & 2.2343 & Reject at $10 \%$ \\
\hline Lignite $\rightarrow$ Oil & 5 & 2.5495 & Reject at $5 \%$ \\
\hline
\end{tabular}

Table 5.2: Granger Causality Test Results for Oil and Average Bituminous Prices

\begin{tabular}{|l|l|l|l|}
\hline Direction of causality & Number of lags & F values & Decision (Ho: No causality) \\
\hline Oil $\rightarrow$ Bituminous & 1 & 0.1892 & Do not reject \\
\hline Bituminous $\rightarrow$ Oil & 1 & 5.0555 & Reject at 5\% \\
\hline Oil $\rightarrow$ Bituminous & 2 & 1.2146 & Do not reject \\
\hline Bituminous $\rightarrow$ Oil & 2 & 4.0306 & Reject at 5\% \\
\hline Oil $\rightarrow$ Bituminous & 3 & 0.7904 & Do not reject \\
\hline Bituminous $\rightarrow$ Oil & 3 & 3.6310 & Reject at $5 \%$ \\
\hline Oil $\rightarrow$ Bituminous & 4 & 0.7060 & Do not reject \\
\hline Bituminous $\rightarrow$ Oil & 4 & 3.1245 & Reject at $5 \%$ \\
\hline Oil $\rightarrow$ Bituminous & 5 & 0.8361 & Do not reject \\
\hline Bituminous $\rightarrow$ Oil & 5 & 3.3580 & Reject at $1 \%$ \\
\hline
\end{tabular}

Table 5.3: Granger Causality Test Results for Oil and Average Anthracite Prices

\begin{tabular}{|l|l|l|l|}
\hline Direction of causality & Number of lags & F values & Decision (Ho: No causality) \\
\hline Oil $\rightarrow$ Anthracite & 1 & 2.8483 & Reject at $10 \%$ \\
\hline Anthracite $\rightarrow$ Oil & 1 & 9.0113 & Reject at $1 \%$ \\
\hline Oil $\rightarrow$ Anthracite & 2 & 5.4632 & Reject at $1 \%$ \\
\hline Anthracite $\rightarrow$ Oil & 2 & 7.3451 & Reject at $1 \%$ \\
\hline Oil $\rightarrow$ Anthracite & 3 & 3.6299 & Reject at $5 \%$ \\
\hline Anthracite $\rightarrow$ Oil & 3 & 7.0785 & Reject at $1 \%$ \\
\hline Oil $\rightarrow$ Anthracite & 4 & 1.0780 & Do not reject \\
\hline Anthracite $\rightarrow$ Oil & 4 & 4.9256 & Reject at $1 \%$ \\
\hline Oil $\rightarrow$ Anthracite & 5 & 1.0947 & Do not reject \\
\hline Anthracite $\rightarrow$ Oil & 5 & 5.3630 & Reject at $1 \%$ \\
\hline
\end{tabular}


Table 5.4: Granger Causality Test Results for Oil and Average Coal Prices

\begin{tabular}{|l|l|l|l|}
\hline Direction of causality & Number of lags & F values & Decision (Ho: No causality) \\
\hline Oil Coal & 1 & 0.9771 & Do not reject \\
\hline Coal Oil & 1 & 2.6456 & Do not reject \\
\hline Oil Coal & 2 & 1.4098 & Do not reject \\
\hline Coal Oil & 2 & 2.0245 & Do not reject \\
\hline Oil Coal & 3 & 0.9733 & Do not reject \\
\hline Coal Oil & 3 & 1.3807 & Do not reject \\
\hline Oil Coal & 4 & 0.6488 & Do not reject \\
\hline Coal Oil & 4 & 0.9966 & Do not reject \\
\hline Oil Coal & 5 & 0.4704 & Do not reject \\
\hline Coal $\quad$ Oil & 5 & 1.4921 & Do not reject \\
\hline
\end{tabular}

The Granger Causality Test results suggest that the causal relationship between the U.S. average coal prices and crude oil prices is not statistically significant. This result applies only when coal prices are averaged over the three types of coal. However, the average lignite prices and average anthracite prices both affect crude oil prices and vice versa. The average bituminous prices have an impact on crude oil prices but the opposite does not hold. It appears that prices for different types of coal influence crude oil prices.

According to the Granger Causality Test results, the prices of specific coal qualities and oil generally have a causal relationship and, technically, this type of correlation is expected to become stronger in the future when it comes to bituminous and lignite because bituminous and lignite will be the most commonly used coals for coal liquefaction (Kimber, 2000). One reason why anthracite showed a more significant relationship with crude oil in the past was that high quality coal is more substitutable for oil than low quality coal (Bituminous and lignite). Based on the EIA's forecast that coal liquefaction and other alternative fuels will increase rapidly over the next 20 years, it is reasonable to believe that low quality coal will exhibit a stronger and stronger trend to replace oil. High quality coal is more likely used to substitute for oil in many fields such as chemical plants and power plants. Moreover, without stable supplies of cheap coal the prices 
of crude oil and natural gas would have been much more volatile. Coal has thus made a significant contribution to the price stability of the entire energy system. The reason why the average coal price does not show a causal relationship with oil can be attributed to the fact that the low quality coal accounts for a majority of the total coal production and that underlying trends in the proportion of specific coal of various qualities distort the true coal price impacts.

The purpose of the Granger Causality Test is to identify the relationship between coal and oil prices. According to the results, a positive correlation matrix of input and output prices can be established by analyzing and simulating the financial outcomes to assess market risk. The correlation between coal and oil prices can have a significant impact on the coal liquefaction project's profitability. It clearly relates input and output streams that are usually thought not to have a downstream or upstream relationship. The Granger Causality Test results provide the statistical evidence for a positive correlation between the prices of coal of specified quality and oil and can be viewed as the fundamental base for market risk analysis.

\subsection{West Virginia Coal Conversion Project Risk Analysis}

\subsubsection{Parameters and Deterministic Benefit-Cost Analysis}

The cash flow model for the benefit-cost analysis in this section comes from the proposed coal liquefaction project in West Virginia (Harris, 2005). Harris and his research team conducted a preliminary feasibility study of a proposed coal conversion project in West Virginia. Based on the Harris feasibility study, the proposed coal conversion plant is assumed to use 5100 tons of coal per day and have a production capacity of 8200 barrels of Ultra Low Sulfur Diesel (ULSD) and 1400 barrels of naphtha per day. The project's expected lifetime is 30 years following a construction period of 3 years. IRR and NPV are computed for six different technology combinations, that is, GSP Rentech, Shell Sasol, GE Sasol, Shell Rentech, GE Rentech and Con Ph Rentech. Since there are no significant differences among the different technologies in terms 
of market risk analysis, the GSP Rentech technology is chosen for NPV simulation and risk assessment. The initial investment for the GSP Rentech project is estimated at about $\$ 584.5$ million, including coal handling, an ASU O2 Plant, Gas/SG Pure and other infrastructure costs. The ULSD price of $\$ 81.90$ per barrel is based on an estimate that $80 \%$ of the product is sold at \$2.00 per gallon (or \$84 per barrel) and 20\% at the lower bound of the market price. Oil price at delivery is likely to fall between $\$ 47.50$ and $\$ 85.50$ per barrel in 2004 dollars. Based upon the relationship between diesel and crude oil over the last 24 months, a diesel price multiplier of $119.4 \%$ of crude oil price per barrel plus $\$ 8.40$ per barrel for the ULSD premium. The conversion factor for a barrel of LPG to Million Btu is 3.618. This gives \$16.97 is price of LPG in terms of \$/Million Btu in 2004 dollars.

From a financial perspective, there are two portions of loans in this project. The base interest rate is assumed to be $6.0 \%$. The asset secured debt terms should be an interest of a base rate plus $1.0 \%, 1.25 \%$, or $1.5 \%$ based on the perceived risk of the project. Interest rate starts at $7.5 \%$ and then decreases in two years to $7.25 \%$ and to $7.0 \%$ at the fourth year. The principal will be paid back in 20 years. Assume the second portion of the debt should have an interest of base rate plus $1.5,2.5$, or $3.5 \%$. The initial interest rate on the second debt would start at $9.5 \%$, subsequently reduced to $8.5 \%$ in the second year and $7.5 \%$ in the fourth year until paid. Assume this debt would be retired over 10 years and the discounting rate is set equivalent to the base rate 7\%. The inflation rate applied in the cash flow is converted from NASA ${ }^{1}$ inflation index 1.222 between 2010 and 2020. Table 5.5 below is abstracted from the GSP Rentech’s cash flow statement.

\footnotetext{
${ }^{1}$ This is an inflation calculator for adjusting costs from one year to another using the NASA New Start Inflation Index. http://cost.jsc.nasa.gov/inflation/nasa/inflateNASA.html.
} 
Table 5.5: Financial Statement Abstract of "West Virginia Coal Conversion Preliminary Feasibility Study"

\section{Parameters and Assumptions}

Duration of Construction, yrs 3

Life of the Project, yrs 30

Coal Processing Capacity, t/d 5000

Days of Production per Year, d/y 310

\begin{tabular}{|c|c|c|}
\hline Major Input & Quantity & Unit Price, \$ \\
\hline Coal, t/d & 5100 & 43.2 \\
\hline Air, $t / d$ & 14808 & \\
\hline $\mathrm{O}_{2}, \mathrm{t} / \mathrm{d}$ & 4282 & \\
\hline Water, t/d & 4000 & 0.25 \\
\hline Steam, t/d & 6780 & \\
\hline \multirow[t]{2}{*}{ Chemicals, t/d } & 0.5 & 1000 \\
\hline & & Case 1 \\
\hline Major Output & Quantity & Unit Price, \$ \\
\hline LPG, BPD & 400 & 73.9 \\
\hline Ultra Low Sulfur Diesel, BPD & 8200 & 81.9 \\
\hline Naphtha, BPD & 1400 & 56.2 \\
\hline Ammonia, $\mathrm{t} / \mathrm{d}$ & 11.6 & 205.7 \\
\hline Sulfur, $\mathrm{t} / \mathrm{d}$ & 45.5 & 30.1 \\
\hline $\mathrm{CO}_{2}, \mathrm{t} / \mathrm{d}$ & 430 & 0 \\
\hline \multicolumn{3}{|l|}{ Steam, } \\
\hline Electricity, MW & 12 & 0 \\
\hline Slag, t/d & 1250 & -1.25 \\
\hline Initial Investment & & GSP/Rentech \\
\hline Coal Handling, Million \$ & & 30 \\
\hline ASU $\mathrm{O}_{2}$ Plant, Million \$ & & 80 \\
\hline Gas/SG Pure, Million \$ & & 195 \\
\hline Infrastructure, Million \$ & & 84.5 \\
\hline F/T, Million \$ & & 78 \\
\hline Power, Million \$ & & 117 \\
\hline Total, M \$ & & 584.5 \\
\hline Salvage Value at end of project, Million \$ & & 29.2 \\
\hline Direct Production Cost per Year & Price & Cost \\
\hline Coal Input, Million \$ & 43.2 & 68.3 \\
\hline Water Input, Million \$ & 0.25 & 0.3 \\
\hline Chemical Input, Million \$ & 1000 & 0.16 \\
\hline Other costs, Million \$ & & 35.6 \\
\hline
\end{tabular}




$\begin{array}{ll}\text { Real Price Change for Crude Oil 1966-2005 } & 2.31 \% \\ \text { Interest Rate } & 9.5-7.0 \% \\ \text { Inflation Rate } & 2.03 \% \\ \text { Dis Rate const } & 7.00 \% \\ \text { Debt/Equity Ratio } & 0.7 \\ \text { Fixed Assets/Investment Ratio } & 0.6 \\ \text { Federal Income tax rate } & 34.00 \% \\ \text { Years of Depreciation } & 20\end{array}$

\section{NPV and IRR}

NPV (Million USD) 931.43

\begin{tabular}{lll} 
& Current & Constan \\
IRR & $25 \%$ & $22.5 \%$ \\
\hline
\end{tabular}

(Source: West Virginia Coal Conversion Preliminary Feasibility Study)

The input and output of coal liquefaction are not simply coal and crude oil according to the cash flow model. The GSP Rentech technology shows that the inputs are primarily coal, while the outputs are ultra low sulfur diesel (ULSD), ammonia, sulfur, naphtha and some other chemicals. ULSD accounts for about $85.71 \%$ of total outputs values, while naphtha and LPG together account for approximately $13.81 \%$ and other outputs for about $0.47 \%$, respectively (see table 5.6). By calculation, the cost of coal use is about $68 \%$ of total production cost, while the cost of water and air together only account for less than $1 \%$. There is no evidence that indicates a significant relationship between ammonia and sulfur with coal prices. Therefore, to simplify the calculations, the distribution and standard errors are estimated only for coal, LPG, ULSD and naphtha, which are thought to be the primary sources of the market risk associated with coal liquefaction and account for approximately 99.5\% of total inputs and outputs. 
Table 5.6: Outputs Composition of WV Coal Conversion Project

\begin{tabular}{|l|l|}
\hline Major Outputs & $\%$ in value \\
\hline LPG & $3.77 \%$ \\
\hline Ultra Low Sulfur Diesel & $85.71 \%$ \\
\hline Naphtha & $10.04 \%$ \\
\hline Ammonia & $0.30 \%$ \\
\hline Sulfur & $0.17 \%$ \\
\hline CO2 & $0.00 \%$ \\
\hline Steam & $0.00 \%$ \\
\hline Electricity & $0.00 \%$ \\
\hline
\end{tabular}

(Source: West Virginia Coal Conversion Preliminary Feasibility Study)

\subsubsection{Standard Errors of Coal and Oil Prices}

The prices of coal and other products used in NPV simulation are from "West Virginia Coal Conversion Preliminary Feasibility Study” (Harris, 2005). The standard deviation and variance are measures of absolute variation, that is, they measure the actual amount of variation present in a set of data, and they are dependent on the scale of measurement (Miller, 1965). To compare and estimate the standard errors in several sets of data, it is generally desirable to use the Coefficient of Variation (CV). The calculation of CV and standard error is as follows:

$$
\begin{aligned}
& s e(x)=\sqrt{\frac{\sum_{i=1}^{n}\left(x_{i}-\bar{x}\right)^{2}}{n-1}} \\
& C V=\frac{s e}{\bar{x}} \cdot 100 \\
& \text { Estimated } \operatorname{se}(\hat{x})=\frac{C V \cdot \hat{x}}{100}
\end{aligned}
$$

where, $\bar{x}$ is the mean value of a sample and $\hat{x}$ is the estimated value; and estimated se $(\hat{x})$ is the estimated standard error of $\hat{x}$. In this analysis, nominal bituminous prices are used to calculate the standard errors of the coal prices. Since ultra low sulfur diesel (ULSD), naphtha and liquefied petroleum gas (LPG) are generally thought to be the downstream products of crude oil, their 
standard errors can be estimated based on the crude oil prices. Based upon the relationship between diesel and crude over the last 24 months, the ULSD price multiplier will be $119.4 \%$ of crude per barrel plus $\$ 8.40 / \mathrm{bbl}$ for the ULSD premium. Table 5.7 presents the estimated standard errors and CVs for bituminous, ULSD, naphtha and LPG. The U.S. average bituminous prices and the average crude oil prices from 1949 to 2004 (EIA, 2006) are applied in this calculation.

Table 5.7: CV and SE for Bituminous, ULSD, Naphtha and LPG

\begin{tabular}{|l|l|l|l|l|}
\hline & Bituminous & ULSD & Naphtha & LPG \\
\hline Expected Price & 43.2 & 90.49 & 56.2 & 73.9 \\
\hline Coefficient of Variation & 65.08 & 83.68 & 83.68 & 83.68 \\
\hline Standard Error & 28.11 & 68.53 & 47.03 & 61.84 \\
\hline
\end{tabular}

\subsubsection{NPV Simulation and Analysis}

Monte Carlo simulation is applied for the risk analysis of the WV coal liquefaction project. The correlation coefficients between bituminous, LPG and oil prices are calculated based on the same data set used in CV and SE computation. As naphtha and ULSD both are the downstream products of crude oil, correlation coefficients between crude oil, bituminous and LPG are used to approximate those between coal, naphtha and ULSD. The correlation coefficient matrix is shown in table 5.8:

Table 5.8: Correlation Coefficient Matrix for LPG, Bituminous and Crude Oil

\begin{tabular}{|l|l|l|l|}
\hline & LPG & Bituminous & Oil \\
\hline LPG & 1 & & \\
\hline Bituminous & 0.885447 & 1 & \\
\hline Oil & 1 & 0.885447 & 1 \\
\hline
\end{tabular}

All the inputs and outputs prices are assumed to follow normal distributions, because a normal distribution fits better with most economic variables than any other type of distribution. Since it doesn't make any sense from an economic perspective that prices take a negative value, truncated normal distributions are used for inputs and outputs prices, whose minimum values are 
set zeros and maximum values set positive infinities. As in Microsoft Excel, when IRR takes a negative value, it is not able to display correct. Therefore, NPV is chosen as the target for simulation. The iteration number was set at 5000 and the outcome includes NPV's distribution, expected value, regression sensitivity and summary statistics. @RISK includes a convergence monitoring capability to help evaluate the stability of the output distributions during a simulation. As more iterations are run, more "stable" output distributions would be as the statistics describing each distribution change less and less with additional iterations. The “convergence monitor” option can help to run enough iteration so that the statistics generated on the outputs are reliable and random. The simulation process includes two parts, the first one without correlation matrix and the second one with a correlation matrix between input and output. The software package “@risk” is used for the simulation and the results are summarized in figures 5.1 and 5.2 . 


\section{Simulation Results for NPV / E93}

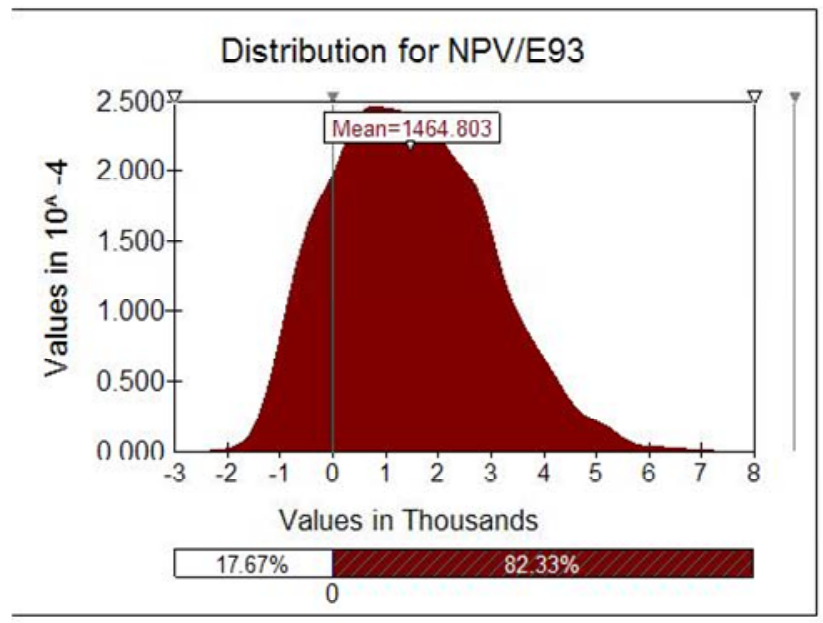

\begin{tabular}{|l|c|}
\hline \multicolumn{2}{|c|}{ Summary Information } \\
\hline Workbook Name & simulation.xls \\
\hline Number of Simulations & 1 \\
\hline Number of Iterations & 5000 \\
\hline Number of Inputs & 4 \\
\hline Number of Outputs & 1 \\
\hline Sampling Type & $7 / 26 / 200620: 31$ \\
\hline Simulation Start Time & $7 / 26 / 200620: 40$ \\
\hline Simulation Stop Time & $00: 09: 18$ \\
\hline Simulation Duration & 2062762289 \\
\hline Random Seed &
\end{tabular}

\begin{tabular}{|l|r|r|r|}
\hline \multicolumn{5}{|c|}{ Summary Statistics } \\
\hline Statistic & \multicolumn{1}{|c|}{ Value } & $\%$ tile & \multicolumn{1}{c|}{ Value } \\
\hline Minimum & -2596.51 & $5 \%$ & -753.21 \\
\hline Maximum & 7299.23 & $10 \%$ & -390.73 \\
\hline Mean & 1464.80 & $15 \%$ & -143.15 \\
\hline Std Dev & 1467.79 & $20 \%$ & 128.65 \\
\hline Variance & 2154411.06 & $25 \%$ & 362.45 \\
\hline Skewness & 0.355152822 & $30 \%$ & 569.06 \\
\hline Kurtosis & 2.771689711 & $35 \%$ & 764.53 \\
\hline Median & 1374.68 & $40 \%$ & 970.43 \\
\hline Mode & 1803.84 & $45 \%$ & 1165.45 \\
\hline Left X & 0.00 & $50 \%$ & 1374.68 \\
\hline Left P & $17.67 \%$ & $55 \%$ & 1578.11 \\
\hline Right X & 4018.14 & $60 \%$ & 1792.36 \\
\hline Right P & $100 \%$ & $65 \%$ & 2002.96 \\
\hline Diff X & 4018.14 & $70 \%$ & 2233.35 \\
\hline Diff P & $82.33 \%$ & $75 \%$ & 2483.04 \\
\hline \#Errors & & $80 \%$ & 2726.92 \\
\hline Filter Min & & $85 \%$ & 3023.81 \\
\hline Filter Max & & $90 \%$ & 3423.88 \\
\hline \#Filtered & 0 & $95 \%$ & 4018.14 \\
\hline
\end{tabular}

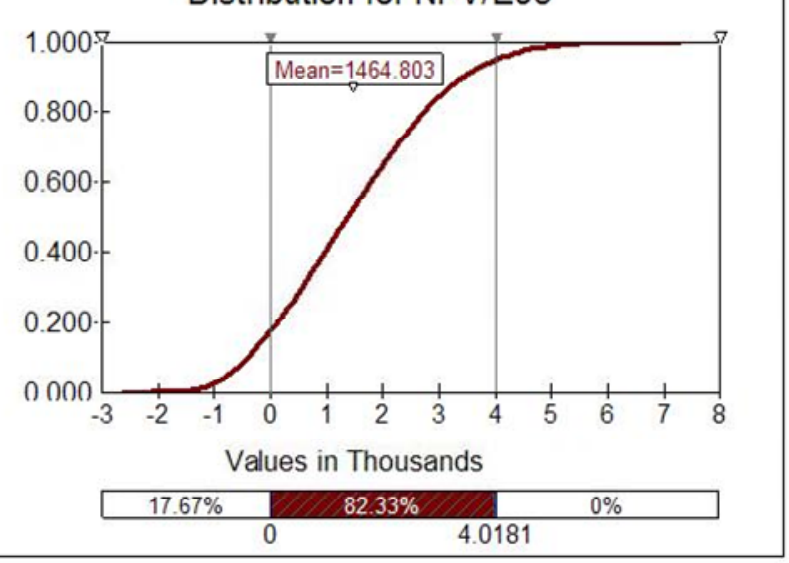

\#Filtered

\begin{tabular}{|l|l|r|r|}
\hline \multicolumn{5}{|c|}{ Sensitivity } \\
\hline \multicolumn{1}{|c|}{ Rank } & \multicolumn{1}{|c|}{ Name } & Regr & \multicolumn{1}{c|}{ Corr } \\
\hline$\# 1$ & Ultra Low Sulfur & 0.955 & 0.956 \\
\hline$\# 2$ & Coal, t/d / Unit Pr & -0.259 & -0.257 \\
\hline$\# 3$ & Naphtha, BPD / & 0.109 & 0.105 \\
\hline$\# 4$ & LPG, BPD / Unit & 0.041 & 0.061 \\
\hline$\# 5$ & & & \\
\hline$\# 6$ & & & \\
\hline$\# 7$ & & & \\
\hline$\# 8$ & & & \\
\hline$\# 9$ & & & \\
\hline$\# 10$ & & & \\
$\# 11$ & & & \\
\hline$\# 12$ & & & \\
\hline$\# 13$ & & & \\
$\# 14$ & & & \\
$\# 15$ & & & \\
\hline 16 & & & \\
\hline
\end{tabular}

Figure 5.1: NPV Simulation Result (without correlation) of West Virginia Coal Conversion Project 


\section{Simulation Results for NPV / E93}

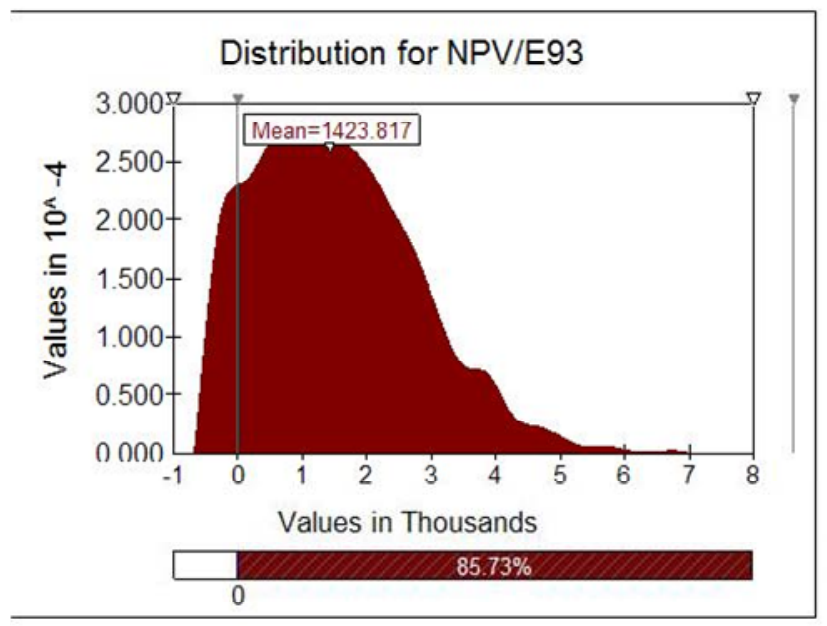

\begin{tabular}{|l|c|}
\hline \multicolumn{2}{|c|}{ Summary Information } \\
\hline Workbook Name & simulation.xIs \\
\hline Number of Simulations & 1 \\
\hline Number of Iterations & 5000 \\
\hline Number of Inputs & 1 \\
\hline Number of Outputs & Monte Carlo \\
\hline Sampling Type & $7 / 26 / 200620: 54$ \\
\hline Simulation Start Time & $7 / 26 / 200621: 04$ \\
\hline Simulation Stop Time & $00: 09: 39$ \\
\hline Simulation Duration & 644787099 \\
\hline Random Seed &
\end{tabular}

\begin{tabular}{|l|r|r|r|}
\hline \multicolumn{5}{|c|}{ Summary Statistics } \\
\hline Statistic & \multicolumn{1}{|c|}{ Value } & \%tile & \multicolumn{1}{c|}{ Value } \\
\hline Minimum & -859.21 & $5 \%$ & -483.95 \\
\hline Maximum & 7087.18 & $10 \%$ & -230.27 \\
\hline Mean & 1423.82 & $15 \%$ & 25.09 \\
\hline Std Dev & 1299.26 & $20 \%$ & 227.70 \\
\hline Variance & 1688069.385 & $25 \%$ & 411.10 \\
\hline Skewness & 0.525097443 & $30 \%$ & 605.00 \\
\hline Kurtosis & 2.961331257 & $35 \%$ & 789.29 \\
\hline Median & 1297.75 & $40 \%$ & 959.67 \\
\hline Mode & 1109.72 & $45 \%$ & 1125.07 \\
\hline Left X & 0.00 & $50 \%$ & 1297.75 \\
\hline Left P & $14.27 \%$ & $55 \%$ & 1486.33 \\
\hline Right X & 3771.08 & $60 \%$ & 1670.84 \\
\hline Right P & $100 \%$ & $65 \%$ & 1876.84 \\
\hline Diff X & 3771.08 & $70 \%$ & 2053.86 \\
\hline Diff P & $85.73 \%$ & $75 \%$ & 2282.14 \\
\hline$\#$ Errors & 0 & $80 \%$ & 2515.29 \\
\hline Filter Min & & $85 \%$ & 2801.88 \\
\hline Filter Max & & $90 \%$ & 3167.34 \\
\hline$\#$ Filtered & 0 & $95 \%$ & 3771.08 \\
\hline
\end{tabular}

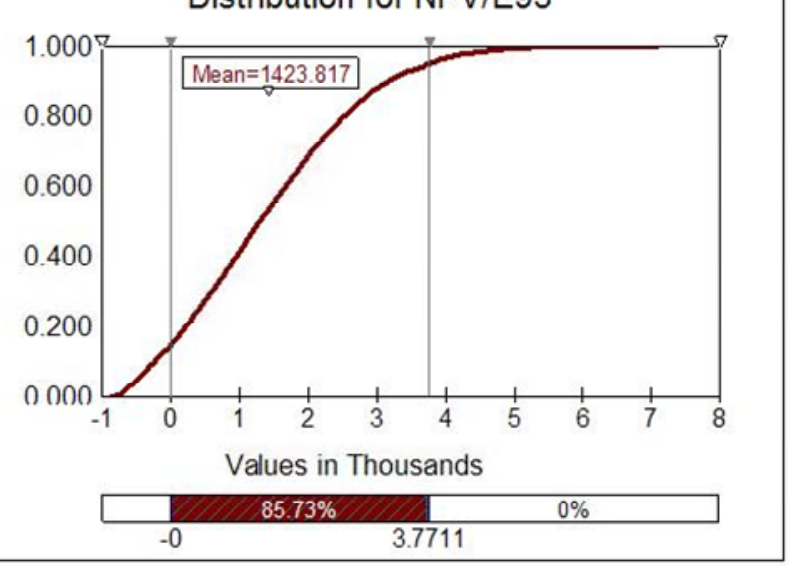

\begin{tabular}{|l|c|r|r|}
\hline \multicolumn{5}{|c|}{ Sensitivity } \\
\hline \multicolumn{1}{|c|}{ Rank } & Name & Regr & \multicolumn{1}{c|}{ Corr } \\
\hline$\# 1$ & Ultra Low Sulfur & 1.079 & 0.990 \\
\hline$\# 2$ & Coal, t/d / Unit Pr & -0.293 & 0.805 \\
\hline$\# 3$ & Naphtha, BPD / & 0.123 & 0.990 \\
\hline$\# 4$ & LPG, BPD / Unit & 0.047 & 0.990 \\
\hline$\# 5$ & & & \\
\hline$\# 6$ & & & \\
\hline$\# 7$ & & & \\
\hline$\# 8$ & & & \\
\hline$\# 9$ & & & \\
\hline$\# 10$ & & & \\
\hline$\# 11$ & & & \\
\hline$\# 12$ & & & \\
$\# 13$ & & & \\
$\# 14$ & & & \\
\hline$\# 15$ & & & \\
$\# 16$ & & & \\
\hline & & & \\
\hline
\end{tabular}

Figure 5.2: NPV Simulation Result (with correlation) of West Virginia Coal Conversion Project 
From Figure 5.2, the price correlation case, the simulated NPV approximately follows a truncated normal distribution. The mean NPV of this project is $\$ 1,424$ million, with a standard deviation of $\$ 1,299$ million, which is not significantly different from its expected value. Therefore, we believe the simulation outcome is random and efficient. Based on the the cash flow analysis, the project's current and constant IRR are $28.8 \%$ and $26.2 \%$, respectively. With a minimum of $-\$ 859$ and a maximum of $\$ 7,087$ million, the probability that the project will have a positive NPV is about $85.73 \%$. In comparison, the simulation results without including the effects of correlation between coal and oil prices imply that the probability for this project to have a positive NPV is about $82.33 \%$ with a mean NPV of $\$ 1,465$ million and a standard deviation of $\$ 1,468$ million. These numbers indicate that even though input and output prices are uncertain, the project still has a significant probability of financial viability. Incorporating the effects of positive correlation between input and out prices give a similar NPV while the standard deviation decreases by $12 \%$. Because of oil price fluctuations, the NPV sensitivity analysis implies that market risk is mainly caused by ULSD. This implies that the NPV rises by $\$ 1.07$ million if the unit ULSD price rises by $\$ 1$. In other words, the market risk associated with the coal liquefaction project is primarily due to oil price fluctuations. Coal prices are the second factor for NPV variation but account for a relatively low portion of the total risk.

Technically, market risk is lowered by a positive correlation between input and output prices (the standard deviation drops from $\$ 1,468$ to $\$ 1,299$ million, and the probability of a positive NPV rises from $82.33 \%$ to $85.73 \%$ ). The simulation results imply that the coal liquefaction project is financially feasible with current energy price levels. In order to lower the entire market risk associated with coal liquefaction, more attention should be paid to the effects of the volatility of oil prices. 


\subsubsection{NPV Simulation and Analysis with EIA's Data}

As a comparison to the Harris analysis based on their own forecasted data, the NPV simulations are repeated using EIA data obtained from “Annual Energy Outlook 2006”. The steam coal price is chosen as the most relevant coal price as the coal used in coal liquefaction is primarily steam coal. For ULSD, average distillate fuel is chosen as the closest substitute. Following Harris, a ratio of 1.61 (ULSD/Naphtha) is applied to estimate the naphtha price. All prices are in 2004 dollars. An assumed inflation rate of 2.03\% is used to estimate nominal prices in 2010. The prices, CV and standard errors estimated for coal, ULSD, naphtha and LPG are provided in table 5.9. The simulation process based on the EIA data are identical to that of the the previous simulations. The simulation results are summarized in figures 5.3 and 5.4 .

Table 5.9 : CV and SE for Coal, ULSD, Naphtha and LPG Prices Based on EIA Data

\begin{tabular}{|l|l|l|l|l|}
\hline & Coal & ULSD & Naphtha & LPG \\
\hline Price in 2010 by EIA & 36.06 & 87.39 & 54.28 & 54.65 \\
\hline Coefficient of Variation & 65.08 & 83.68 & 83.68 & 83.68 \\
\hline Standard Error & 23.47 & 73.13 & 45.42 & 45.73 \\
\hline
\end{tabular}




\section{Simulation Results for NPV / E93}

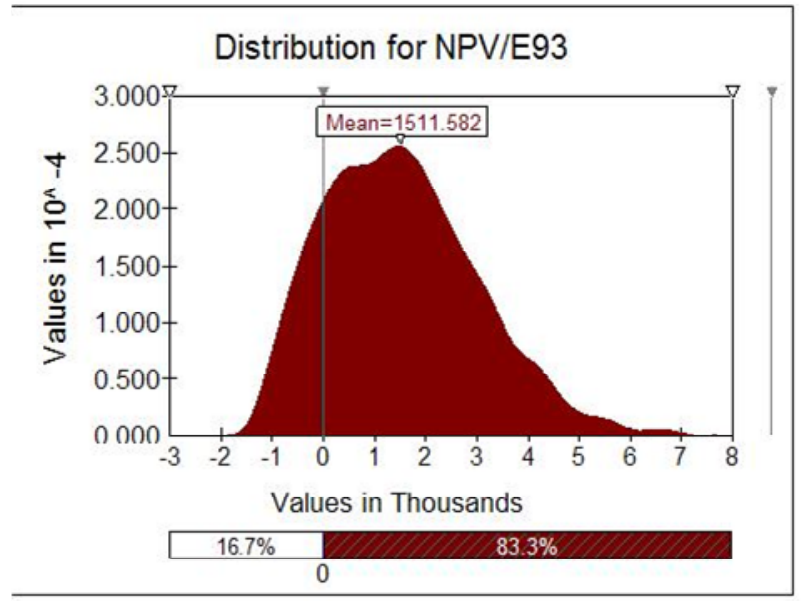

\begin{tabular}{|l|c|}
\hline \multicolumn{2}{|c|}{ Summary Information } \\
\hline Workbook Name & Simulation - ElA.xls \\
\hline Number of Simulations & 1 \\
\hline Number of Iterations & 5000 \\
\hline Number of Inputs & 4 \\
\hline Number of Outputs & 1 \\
\hline Sampling Type & Monte Carlo \\
\hline Simulation Start Time & $7 / 26 / 200621: 20$ \\
\hline Simulation Stop Time & $7 / 26 / 200621: 29$ \\
\hline Simulation Duration & $00: 09: 02$ \\
\hline Random Seed & 1971172204 \\
\hline
\end{tabular}

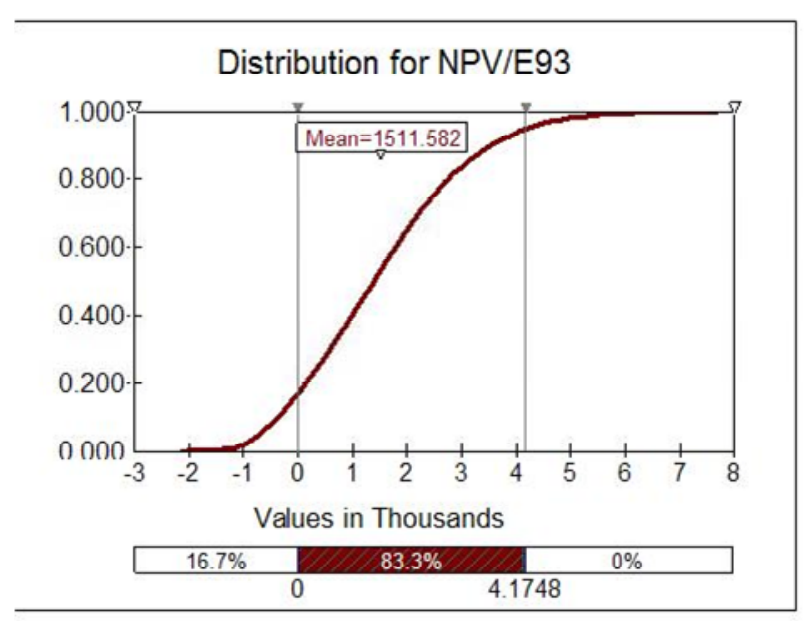

\begin{tabular}{|l|r|r|r|}
\hline \multicolumn{5}{|c|}{ Summary Statistics } \\
\hline Statistic & \multicolumn{1}{|c|}{ Value } & $\%$ tile & \multicolumn{1}{c|}{ Value } \\
\hline Minimum & -2120.49 & $5 \%$ & -704.86 \\
\hline Maximum & 7693.91 & $10 \%$ & -356.30 \\
\hline Mean & 1511.58 & $15 \%$ & -95.03 \\
\hline Std Dev & 1508.56 & $20 \%$ & 153.81 \\
\hline Variance & 2275759.126 & $25 \%$ & 370.36 \\
\hline Skewness & 0.511367582 & $30 \%$ & 597.41 \\
\hline Kurtosis & 3.078963921 & $35 \%$ & 788.39 \\
\hline Median & 1388.31 & $40 \%$ & 990.55 \\
\hline Mode & 1375.11 & $45 \%$ & 1190.52 \\
\hline Left X & 0.00 & $50 \%$ & 1388.31 \\
\hline Left P & $16.70 \%$ & $55 \%$ & 1590.07 \\
\hline Right X & 4174.84 & $60 \%$ & 1791.10 \\
\hline Right P & $100 \%$ & $65 \%$ & 1999.95 \\
\hline Diff X & 4174.84 & $70 \%$ & 2215.23 \\
\hline Diff P & $83.30 \%$ & $75 \%$ & 2482.36 \\
\hline \#Errors & & $80 \%$ & 2751.30 \\
\hline Filter Min & & $85 \%$ & 3106.44 \\
\hline Filter Max & & $90 \%$ & 3533.90 \\
\hline \#Filtered & 0 & $95 \%$ & 4174.84 \\
\hline
\end{tabular}

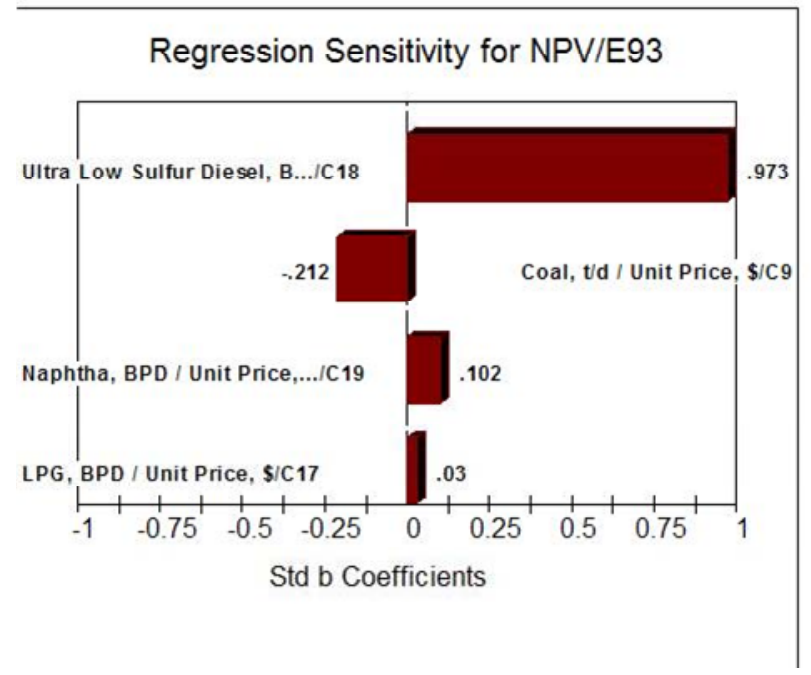

\begin{tabular}{|l|l|r|r|}
\hline \multicolumn{5}{|c|}{ Sensitivity } \\
\hline \multicolumn{1}{|c|}{ Rank } & \multicolumn{1}{|c|}{ Name } & Regr & \multicolumn{1}{c|}{ Corr } \\
\hline$\# 1$ & Ultra Low Sulfur & 0.973 & 0.969 \\
\hline \#2 & Coal, t/d / Unit Pr & -0.212 & -0.201 \\
\hline \#3 & Naphtha, BPD / & 0.102 & 0.096 \\
\hline$\# 4$ & LPG, BPD / Unit & 0.030 & 0.033 \\
\hline$\# 5$ & & & \\
\hline$\# 6$ & & & \\
$\# 7$ & & & \\
\hline$\# 8$ & & & \\
\hline$\# 9$ & & & \\
\hline$\# 10$ & & & \\
\hline 11 & & & \\
\hline$\# 12$ & & & \\
\hline$\# 13$ & & & \\
\hline$\# 14$ & & & \\
\hline 15 & & & \\
\hline 16 & & & \\
\hline
\end{tabular}

Figure 5.3: NPV Simulation Result (without correlation) of West Virginia Coal Conversion Project based on EIA Data 


\section{Simulation Results for NPV / E93}

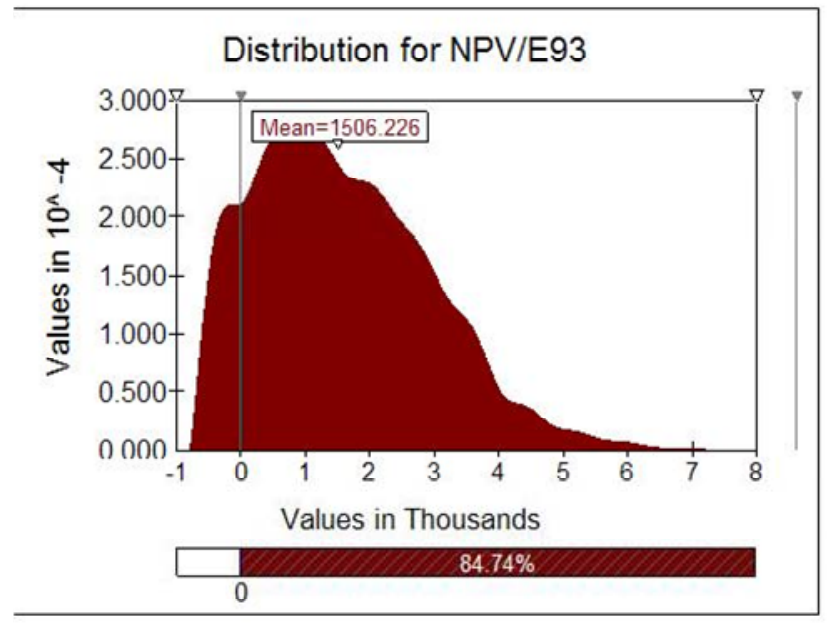

\begin{tabular}{|l|c|}
\hline \multicolumn{2}{|c|}{ Summary Information } \\
\hline Workbook Name & Simulation - ElA.xls \\
\hline Number of Simulations & 1 \\
\hline Number of Iterations & 5000 \\
\hline Number of Inputs & 4 \\
\hline Number of Outputs & Monte Carlo \\
\hline Sampling Type & $7 / 26 / 200621: 44$ \\
\hline Simulation Start Time & $7 / 26 / 200621: 54$ \\
\hline Simulation Stop Time & $00: 10: 12$ \\
\hline Simulation Duration & 501236999 \\
\hline Random Seed &
\end{tabular}

\begin{tabular}{|l|r|r|r|}
\hline \multicolumn{5}{|c|}{ Summary Statistics } \\
\hline Statistic & \multicolumn{1}{|c|}{ Value } & $\%$ tile & \multicolumn{1}{c|}{ Value } \\
\hline Minimum & -975.33 & $5 \%$ & -513.52 \\
\hline Maximum & 7424.58 & $10 \%$ & -245.98 \\
\hline Mean & 1506.23 & $15 \%$ & -11.14 \\
\hline Std Dev & 1395.33 & $20 \%$ & 224.15 \\
\hline Variance & 1946943.85 & $25 \%$ & 416.23 \\
\hline Skewness & 0.548462219 & $30 \%$ & 605.13 \\
\hline Kurtosis & 2.960751229 & $35 \%$ & 796.81 \\
\hline Median & 1354.70 & $40 \%$ & 979.25 \\
\hline Mode & 1137.08 & $45 \%$ & 1148.95 \\
\hline Left X & 0.00 & $50 \%$ & 1354.70 \\
\hline Left P & $15.26 \%$ & $55 \%$ & 1556.64 \\
\hline Right X & 3973.61 & $60 \%$ & 1773.62 \\
\hline Right P & $100 \%$ & $65 \%$ & 1991.13 \\
\hline Diff X & 3973.61 & $70 \%$ & 2208.91 \\
\hline Diff P & $84.74 \%$ & $75 \%$ & 2447.59 \\
\hline \#Errors & & $80 \%$ & 2709.34 \\
\hline Filter Min & & $85 \%$ & 3012.02 \\
\hline Filter Max & & $90 \%$ & 3369.93 \\
\hline \#Filtered & 0 & $95 \%$ & 3973.61 \\
\hline
\end{tabular}

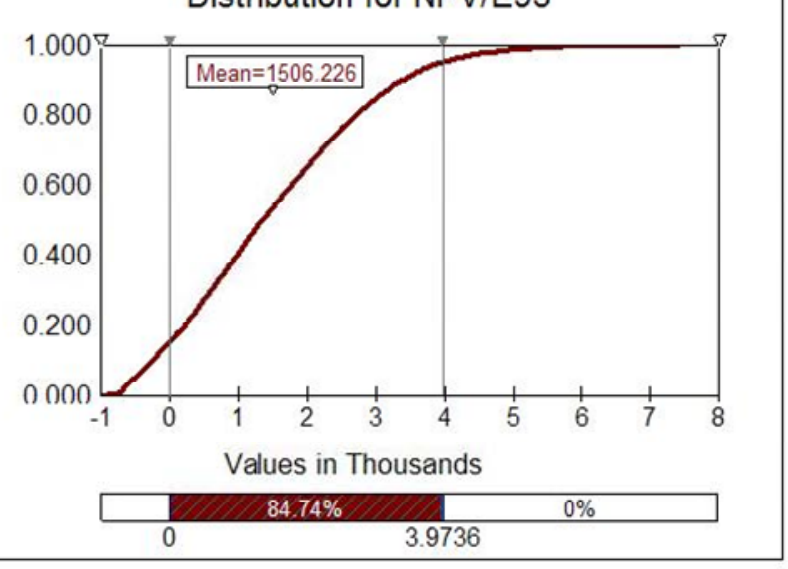

\begin{tabular}{|c|c|c|c|}
\hline \multicolumn{4}{|c|}{ Sensitivity } \\
\hline Rank & Name & Regr & Corr \\
\hline$\# 1$ & Ultra Low Sulfur $\mathrm{d}$ & 1.051 & 0.994 \\
\hline$\# 2$ & Coal, t/d / Unit Pri & -0.227 & 0.817 \\
\hline$\# 3$ & Naphtha, BPD / U & 0.112 & 0.994 \\
\hline$\# 4$ & LPG, BPD / Unit & 0.033 & 0.994 \\
\hline \multicolumn{4}{|l|}{$\# 5$} \\
\hline \multicolumn{4}{|l|}{ \#6 } \\
\hline \multicolumn{4}{|l|}{$\# 7$} \\
\hline \multicolumn{4}{|l|}{$\# 8$} \\
\hline \multicolumn{4}{|l|}{$\# 9$} \\
\hline \multicolumn{4}{|l|}{$\# 10$} \\
\hline \multicolumn{4}{|l|}{$\# 11$} \\
\hline \multicolumn{4}{|l|}{$\# 12$} \\
\hline \multicolumn{4}{|l|}{$\# 13$} \\
\hline \multicolumn{4}{|l|}{$\# 14$} \\
\hline \multicolumn{4}{|l|}{$\# 15$} \\
\hline$\# 16$ & & & \\
\hline
\end{tabular}

Figure 5.4: NPV Simulation Result (with correlation) of West Virginia Coal Conversion Project based on EIA Data 
The simulated NPV results of the two alternatives are statistically similar. The new simulated NPV result also follows a truncated normal distribution. The expected NPV of this project is now $\$ 1,506$ million with a standard deviation of $\$ 1,395$ million. A minimum of $-\$ 975$ million and a maximum of $\$ 7,425$ are obtained. The expected project's constant and current IRR are $33.7 \%$ and $36.4 \%$, respectively. The probability for this project to have a positive NPV is about $84.74 \%$. Without including the effects of the positive correlation of input and output prices, the expected NPV of this project is $\$ 1,512$ million, with a standard deviation of $\$ 1,509$ million. Including the positive correlation between input and out prices gives about the same expected NPV while the standard deviation is lower. Market risk is also lowered (the standard deviation drops from $\$ 1,509$ to $\$ 1,395$ million, approximately $8 \%$, while the probability of a positive NPV rises from $83.3 \%$ to $84.7 \%$, approximately $1.7 \%$ ). The NPV sensitivity analysis reflects that the market risk is mainly caused by ULSD and coal prices are a secondary factor. The expected NPV rises by $\$ 1.05$ million if the unit ULSD price rises by $\$ 1$.

In general, the probability of a negative NPV has been lowered using the EIA data compared to data used in Harris (2005), i.e., with a positive correlation between coal and oil prices, the coal liquefaction project is less likely to lose money, although the result is not overly significant. The financial uncertainty is also lowered due to the positive correlation between coal and oil prices. The new simulation results show a higher project expected NPV and standard deviation based on the EIA data. This shows that the Harris research results are more conservative and cautious. Investors are normally expected to prefer feasibility reports that are more conservative; investors that are considering large investments are more likely to be risk averse. Therefore, for those potential investors, the Harris feasibility study may be preferred as a method the minimize the risk due to future uncertainties involved in coal liquefaction. Both 
simulations reflect a lower market risk due to a positive correlation between input and output prices and indicate that the coal liquefaction project is financially feasible given current energy price levels. The oil price is the single most important factor determining the profitability of the entire project, i.e., future oil price trends determine the feasibility of coal liquefaction projects.

\subsection{Feasibility Comparison with Other Liquid Fuel Mitigation Options}

There are other alternatives sources of liquid fuels. Bezdek, et al. (2006) made a comparison of different types of liquid fuel mitigation options, including Vehicle Fuel Efficiency (VFE), Coal Liquefaction (coal to liquids or CTL), Oil Shale and Enhanced Oil Recovery (EOR). Figure 5.5 provides a summary of the relative costs of these options. This study shows that the relative cost for coal liquefaction is about $\$ 42$ per barrel while the average cost of the other three options is about $\$ 60$ per barrel. Coal liquefaction has the second lowest cost among the four options considered and EOR, the only lower cost option, has significant limitations as a large scale source. CTL also has favorable economic impacts. Figure 5.6 indicates the total employment impact per $\$ 1$ million of direct cost for all four options. CTL projects provide over nine jobs per million dollars of investments, the highest jobs creation impact among the four options. Compared to other options, the shortcoming of CTL lies in the complexity of the chemical processes and the high initial capital investment. However, lower average production cost and greater job creation indicated that CTL is financially feasible compared to other liquid fuel mitigation options and potentially preferred by local communities. 


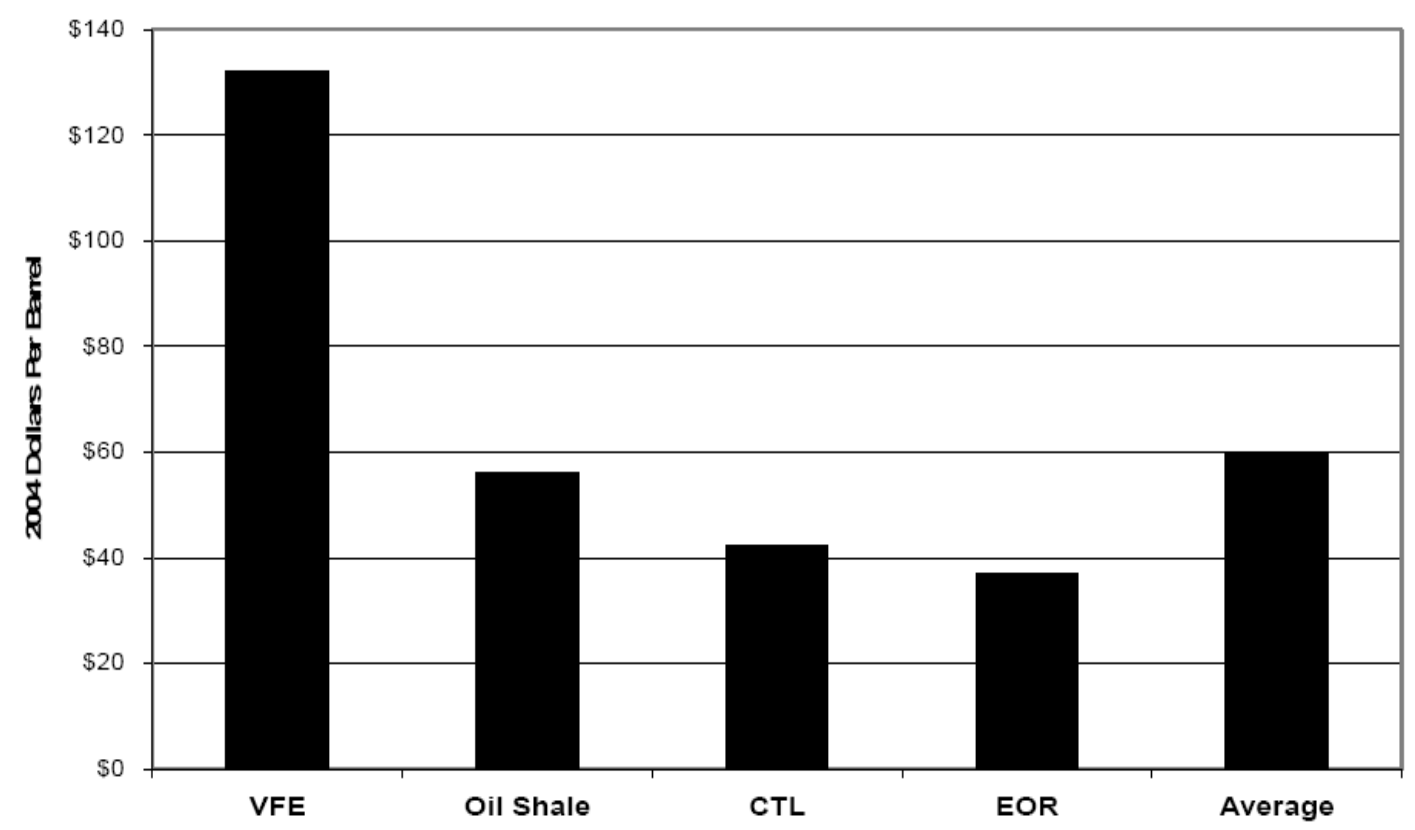

Figure 5.5: Cost Comparison of Different Types of Liquid Fuel Mitigation Options (Source: Economic Impacts of Liquid Fuel Mitigation Options, 2006)

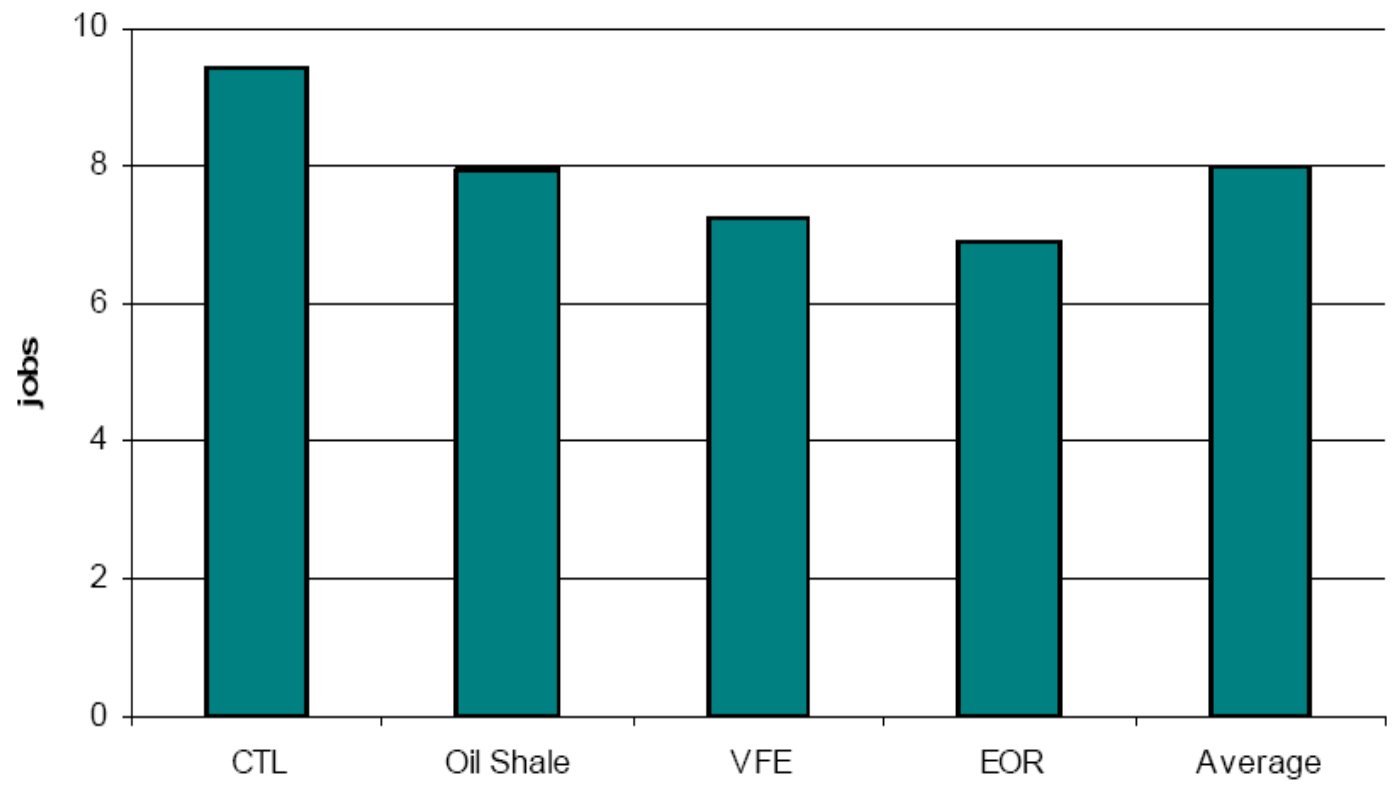

Figure 5.6: Total Employment Impact per \$1 Million of Direct Cost

(Source: Economic Impacts of Liquid Fuel Mitigation Options, 2006) 


\subsection{Investment Returns Comparison with Other Industries}

Porter (2005) studied investment returns and standard deviations of different industries for the period 1951-2001 (table 5.10). The average investment return is about $12.41 \%$ with an average standard deviation of about $12.54 \%$ for all industries. Chemicals and Petroleum Refining have relative high investment returns while Oil \& Gas and coal mining are about average. Compared to these industries' investment returns, coal liquefaction displays a much higher rate of return (22.5\%) and an acceptable standard deviation level (22\%). Inevitably, a high expected rate of return brings high risk. The coal liquefaction ratio of IRR to standard deviation is about 1.022, much higher than Oil \& Gas and coal mining and slightly higher than Chemicals and Petroleum Refining. Therefore, from a financial perspective, the results indicate that coal liquefaction is a good long-term project worth further investigation.

\subsection{Breakeven Point for the West Virginia Coal Conversion Project}

The calculation of breakeven point is based on the information provided by the West Virginia Coal Conversion Project report. In order to obtain a precise breakeven price point for crude oil, the method applied follows that outlined in the Harris feasibility study. According to this approach, the ULSD price reflects $80 \%$ of the product sold at market price and $20 \%$ at the lower bound of the market price (see equation 5.6). Oil price at delivery is likely to fall between \$47.5 and \$85.5 per barrel in 2004 dollars. Based upon the relationship between diesel and crude oil over the last 24 months, the diesel price multiplier will be $119.4 \%$ of crude oil per barrel plus $\$ 8.40 /$ bbl for the ULSD premium (see equation 5.7). The price of ULSD is assumed the average of the upper and lower bounds (see equation 5.8); the ratio of higher bound to lower bound is assumed to have an equivalent ratio to the Harris forecast (see equation 5.9). 
Table 5.10: Industry Investment Returns and Standard Deviations

\begin{tabular}{|c|c|c|c|}
\hline Industry & Investment Return (Mean) & Investment Return Std. Dev. & Ratio of Mean/SD \\
\hline Metal Mining & 7.77 & 7.81 & 0.99 \\
\hline Coal Mining & 10.82 & 12.89 & 0.84 \\
\hline Oil \& Gas & 12.39 & 15.02 & 0.82 \\
\hline Non-Metallic Minerals & 12.43 & 15.40 & 0.81 \\
\hline Food & 13.70 & 12.16 & 1.13 \\
\hline Tobacco & 15.31 & 10.24 & 1.50 \\
\hline Textile Mill Products & 10.14 & 16.31 & 0.62 \\
\hline Apparel & 9.57 & 10.79 & 0.89 \\
\hline Lumber \& Wood & 11.96 & 11.22 & 1.07 \\
\hline Paper & 12.61 & 10.24 & 1.23 \\
\hline Printing \& Publishing & 13.59 & 10.83 & 1.25 \\
\hline Chemicals & 13.47 & 14.47 & 0.93 \\
\hline Petroleum Refining & 14.02 & 14.43 & 0.97 \\
\hline Rubber \& Plastics & 12.63 & 14.53 & 0.87 \\
\hline Leather & 10.92 & 11.28 & 0.97 \\
\hline Stone \& Concrete & 12.31 & 11.28 & 1.09 \\
\hline Primary Metals & 8.99 & 14.41 & 0.62 \\
\hline Fabricated Metal & 11.77 & 10.23 & 1.15 \\
\hline Machinery & 14.00 & 10.80 & 1.30 \\
\hline Electrical Eqpmt. & 15.06 & 11.08 & 1.36 \\
\hline Motor Vehicles & 13.27 & 11.78 & 1.13 \\
\hline Other Trans. Eqpmt. & 14.01 & 15.44 & 0.91 \\
\hline Railroads & 12.81 & 11.90 & 1.08 \\
\hline Air Transport & 11.56 & 17.62 & 0.66 \\
\hline Telephone \& Telegraph & 12.27 & 12.97 & 0.95 \\
\hline Electric \& Gas Service & 10.56 & 11.98 & 0.88 \\
\hline Wholesale Trade & 12.22 & 10.79 & 1.13 \\
\hline Retail Trade & 12.67 & 13.96 & 0.91 \\
\hline Motion Pictures & 15.81 & 11.20 & 1.41 \\
\hline
\end{tabular}

(Source: Connecting Optimal Capital Investment and Equity Returns, Porter, 2005) 


$$
\begin{array}{ll}
0.8 \cdot P_{\text {Diesel }}+0.2 \cdot P_{\text {Diesel low }}=P_{\text {ULSD }} & \text { (Equation 5.6) } \\
P_{\text {Diesel }}=1.194 \cdot P_{\text {Crude }}+8.4 & \text { (Equation 5.7) } \\
P_{\text {Diesel }}=\frac{P_{\text {Diesel, high }}+P_{\text {Diesel,low }}}{2} & \text { (Equation 5.8) } \\
\frac{P_{\text {Crude, high }}}{P_{\text {Crude, low }}}=\frac{85.5}{47.5} & \text { (Equation 5.9) }
\end{array}
$$

The prices of LPG and naphtha are closely related to the crude oil price, therefore, three products have prices that vary with a fixed ratio. The breakeven point for the entire project is to find a critical price that makes the NPV of project equal zero. In order to make the result close to today's price level so that it is easy for investors to evaluate, the 2004 bituminous price was chosen as the input coal price, and all the prices in this calculation are nominal and include an inflation factor. By calculation, the ULSD price is $\$ 61 / \mathrm{bbl}$ at the breakeven point. Therefore, a breakeven point price of $\$ 46.72 /$ bbl for crude oil was derived based on equations 5.6-5.9. This number indicates that if the project was initiated in 2004, it would make a constant IRR as high as the interest rate if the crude oil price remains constant at $\$ 46.72 / \mathrm{bbl}$ in 2004 dollars over the following 30 years. That is, this project is profitable as long as the average crude oil price is higher than $\$ 46.72 /$ bbl in the following 30 years. 


\section{Chapter Six - Summary and Conclusions}

\subsection{Introduction}

This chapter provides a summary of the study with additional discussion related to future development of coal liquefaction. A discussion of the implications of the research follows. The limitations of the study are then discussed followed by the final section which concludes with directions for future research.

\subsection{Summary of Study}

This study discusses the different types of risks associated with coal liquefaction. Risks related to coal liquefaction are diverse but interrelated. Among the risks associated with coal liquefaction projects, market risk is the one of the biggest problems in converting technologies from the laboratory into commercial-scale, financially viable projects. This study focuses on the analysis of market risk and points out that market risk related to coal liquefaction is mainly due to fluctuations in input and output market prices. Financial derivatives are applied as a method of mitigating the market risk of coal liquefaction projects. When the oil price remains at a high level, the market risk of coal liquefaction projects decrease significantly. A positive correlation between coal and oil prices further lowers the market risk of a project. According to an EIA forecast, oil prices are expected to stay at unprecedented high levels and even increase over the next 25 years. These factors provide an opportunity for the development of coal liquefaction projects. In chapter five, Granger Causality Test conducted for alternative measures of U.S. average coal and oil prices show that these prices have a two way causal relationship for certain types of coal, lignite and anthracite.

This study uses a proposed coal conversion project in West Virginia as a case study for market risk analysis. Using the estimated standard errors, Monte Carlo simulations performed to 
access the financial viability of the WV coal liquefaction project indicate that the project has a high probability of profitability and is financially feasible. The results feature a high expected NPV and an acceptable standard deviation. Therefore, we conclude that the risk level of the proposed West Virginia coal liquefaction project is acceptable based on the 2005 EIA energy price predictions.

The overall conclusion of the analysis is that a crude oil price of $\$ 46.72$ in 2004 dollars is sufficient to cover all economic costs; higher oil prices result in greater economic profits. This compares with ongoing developments in China where information from the Shenhua Group developing the first commercial coal liquefaction facility in China indicates that "their products out of coal liquefaction are still going to be competitive in the market even if the oil price drops to a range between $\$ 25 \sim$ 35 per barrel” (Ren, 2006). Based on past performance, the real cost of liquid fuels from coal can be expected to decrease as the technology improves and operating efficiencies are developed.

\subsection{Implications of the Research}

Commercialization of coal liquefaction is expected to have a significant impact on energy markets. Operating a commercial coal liquefaction plant will be expensive, but its products can find a ready market as world oil production declines. Once coal liquefaction technology has been widely commercialized, the interdependencies in coal and oil supply is expected to be more apparent. Therefore, the dominant role of oil in world energy markets may be challenged in the future. The price of oil will be limited to some extent as coal liquefaction technologies mature and are commercialized. "South African gasoline production from coal is competitive at an oil price in the $\$ 45$ per barrel range. It seems intuitively clear that any technology if forced to grow in output by three orders of magnitude could drive prices down by at least another factor of two" 
(Lackner, 2004). This suggests that synthetic fuels from coal would be no more expensive in the long run than petroleum based fuels that have been for most of the last 30 years. Oil price equivalents could be held at lower levels because of competition from coal derived liquid fuels. Therefore, the detrimental effect of oil crises could be mitigated. This technology increases the substitutability among fossil fuels. As a result, current fossil energy resources could last for centuries. Coal liquefaction and other alternatives to crude oil may provide energy at prices that could drop well below today's energy prices to the $\$ 90 / \mathrm{bbl}$ range, suggesting that technologies that could gradually lower the cost of alternative energy resources would help stabilize the price of energy worldwide (Lackner, 2006).

Governmental supports are important to the initial development of coal liquefaction. The initial capital and operating costs for a coal liquefaction plant are so high that, given perceived market risks, private investors refrain from investing in such projects. Coal liquefaction is developing rapidly in China primarily due to the fact that state-owned companies are responsible for coal liquefaction projects and have strong support from the China's central government. In the U.S., where the investment market is primarily private, government purchases can play an important role in supporting the development of coal liquefaction industry. The majority of market risks involved with coal liquefaction plant can be eliminated by long-term government contracts. On the government's side, the benefits are local job creation, increased investment and tax revenue and a stable source of liquid fuel. On April 24th 2006, President Bush presented his "Four-Point Plan" to control soaring gas prices, the last item of which is "invest aggressively in gasoline alternatives”. Coal liquefaction will benefit from the president's plans and will develop significantly in the U.S. in the near future. 


\subsection{Limitations of the Study}

This study is subject to some obvious limitations. First of all, technical risk should be assessed with detailed engineering data and chemical processes. Besides conversion efficiency, there are still many uncertainties, such as final products' compatibility, that will affect the overall viability of specific technologies. Although this study is focused on market risk analysis, due to methodology limitations, the inputs and outputs prices were treated as random variables at the beginning of the project in NPV simulation. However, all the prices are assumed to increase over the life span of the project and the shortcoming of this treatment in NPV simulation is partially reflected in the results. Statistically, the precision of predicted input and out prices over time needs further discussion. Due to the limited time and resources available for the study, it is difficult to assess adequately the risk factors for coal liquefaction.

\subsection{Directions for Future Research}

This study provided a specific analysis of the market risk associated with a West Virginia coal liquefaction project. Future research can focus on other types of risk of coal liquefaction such as environmental risk, social risk and technical risk.

To improve the market risk analysis, a better forecast of oil and coal prices is needed so that a more precise long term project NPV can be estimated. Better empirical relationships between coal and oil prices will significantly improve the estimation of NPV. As the commercialization of coal liquefaction continues to develop new risks involved in the commercialization can be expected to be exposed and further research on these topics will be required. Technical breakthroughs are always an effective way to lower not only technical risk but also market risk. Future research should pay attention to the evolution of coal liquefaction technologies and improve financial assessments based on technical improvements. 


\section{References}

AIRMIC. 2002. “A Risk Management Standard.” ALARM, http://www.theirm.org/publications/documents/Risk_Management_Standard_030820.pdf

Barnthouse, L.W., and Suter G.W. II (eds.). 1986. User's manual for ecological risk assessment. ORNL-6251. Oak Ridge National Laboratory, Oak Ridge, TN.

Bezdek, R.H., and Wendling, R.M. 2006. “Economic Impact of Liquid Fuel Mitigation Options.” Management Information Services, Inc. http://www.netl.doe.gov/energyanalyses/pubs/Economic\%20Impacts\%20of\%20U.S.\%20Liquid\%20Fuel\%20Mitigation \%200ptions.pdf。

Burt Porter, R. 2005. “Connecting Optimal Capital Investment and Equity Returns.” Financial Management. Summer. Pp. 63-98.

Davis, B. 1997. “Fischer-Tropsch Synthesis.” Energeia. Vol. 8, No. 3, pp. 17-22.

Duffie, D., and Pan, J. 1997. “An Overview of Value at Risk.” The Journal of Derivatives. Vol. 4. No. 3 (Spring). pp. 7-49.

Dufour, J.M., Bernard, J.T., and Khalaf, L. 2004. "Structural change and the dynamics of energy prices.” Journal of Economic Literature classification. C22, C52, C53, Q40.

Energy Information Administration. 2006. “Annual Energy Outlook 2006 with Projections to 2030.” http://www.eia.doe.gov/oiaf/aeo/index.html

Fletcher, J.J., Sun, Q., Bajura, R.A., Zhang, Y., and Ren, X. 2004. “Coal to Clean Fuel - The Shenhua Investment in Direct Coal Liquefaction.” Paper presented at Twenty-First Annual International Pittsburgh Coal Conference, 13-17 September. http://www.engr.pitt.edu/pcc/Missing\%20Papers/243.pdf

Force, T. 2003. “Transforming Coal for Sustainability: A Strategy for China.” Energy for Sustainable Development. Volume 7, No. 4, pp. 33-38

Friedman, F.B. 1997. Practical Guide to Environmental Management. $7^{\text {th }}$. Ed. Environmental Law Institute, Washington, DC.

Gooijer, J.G., Abraham, B., Gould, A., and Robinson, L. 1985. "Methods for Determining the Order of an Autoregressive-Moving Average Process: A Survey.” International Statistical Review, 53, 3, pp. 301-329.

Gujarati, D.N. 2003. Basic Econometrics, $4^{\text {th }}$. ed. McGraw-Hill/Irwin.

Hamdhi, E.B. 1996. "Impact of Uncertain Oil Prices on Investment and Integration Efforts in the Oil and Gas Industry.” Journal of Petroleum Technology. pp. 160-162.

Harris, R. 2003. West Virginia Coal Conversion Preliminary Feasibility Study. Cambridge Associates, Ltd.

Hartz, D.B. 1964. "Risk Analysis in Capital Investments.” Harvard Business Review. pp. 18-32.

International Energy Agency. 1982. Coal Liquefaction --- A Technology Review. Organization for Economic Cooperation and Development. 
Jackson, J.K. 2006. “U.S. Trade Deficit and the Impact of Rising Oil Prices.” Congressional Research Service. http:/vienna.usembassy.gov/en/download/pdf/deficit_oil.pdf.

Kamall, R. 1999. “Technology Status Report - Coal Liquefaction.” Cleaner Coal Technology Programme. Technology Status Report 010.

Kennedy, P. 2003. A Guide to Econometrics, $5^{\text {th }}$. Ed, the MIT Press, Cambridge, Massachusetts.

Kimball, R.C. 2000. "Failures in Risk Management.” New England Economic Review. January/February. pp. 3-12.

Kimber G. 1991. “Petrol and Diesel From Coal: British Coal’s Liquefaction Process.” Energeia. Vol. 2, No. 2, pp. 11-23.

Klein, A. 2002. “Gasification: An Alternative Process for Energy Recovery and Disposal of Municipal Solid Wastes.” Submitted for the degree of M.S. in Earth Resources Engineering. http://www.seas.columbia.edu/earth/kleinthesis.pdf.

Kleindorfer, P.R. 2000. Industrial Ecology and Risk Analysis. Risk Management and Decision Processes Center, The Wharton School, University of Pennsylvania.

Lackner, K.S. 2004. “Energy and Clean Coal.” Working paper, University of Columbia.

Larson, E.D., and Ren, T. 2003. "Synthetic Fuel Production by Indirect Coal Liquefaction.” Energy for Sustainable Development. Volume VII. No. 4. http://www.princeton.edu/ energy/publications/pdf/2003/indirect.pdf.

Manfredo, M.R., and Leuthold, R.M. 1998. “Agricultural Applications of Value-at-Risk Analysis: A Perspective.” OFOR Paper:98-04. http://agebb.missouri.edu/ncrext/ncr134/confp20-98.pdf

Mangold, E.C., Muradaz, M.A., Ouellette, R.P., and Farah, O.G. 1982. Coal Liquefaction and Gasification Technologies. New Jersey Institute of Technology.

Mernitz, K.S.1990. "Firms in Conflict: Liquid Fuel Producers in the U.S. and Germany, 19101933.” Business and Economic History. Second Series. Vol. 19. pp. 143-153.

Micallef, J.V. 1981. “Political Risk Assessment.” Columbia Journal of world business. pp. 6370.

Miller, D. 2003. “Making Friends: West Virginia Coal Needs You.” Presented at West Virginia Coal Association.

Miller, I., and Freund, J.E. 1965. Probability and Statistics for Engineers. Prentice-Hall, INC., Englewood Cliffs, New Jersy.

Myers, S. C. 1976. Using simulation for risk analysis. Modern developments in financial management, S. C. Myers, ed., Praeger, Westport, New York, NY.

National Mining Association. 2004. “Liquid Fuels from U.S. Coal.” URL: http://www.nma.org/pdf/liquid_coal_fuels_100505.pdf

Omole, O., Borisade, T.A., and Muhammad, A. 2004. "Risk impacts on the economic performance of oil and gas projects in Nigeria”, 2004 Organization of the Petroleum Exporting Countries, OPEC Review. pp. 247-274 
Pinceralto, E.J. 1999. “Environmental Risk Assessment Offshore.” Journal of Petroleum Technology. April. pp. 68-72.

Pouliquen, L.Y. 1970. Risk Analysis in Project Appraisal. The Johns Hopkins Press, Baltimore, MD.

Rodger, C., and Petch, J. 1999. “Uncertainty \& Risk Analysis.” Business Dynamics. PricewaterhouseCoopers United Kingdom firm. http://clem.mscd.edu/ mayest/Excel/Files/Uncertainty\%20and\%20Risk\%20Analysis.pdf.

Schierow, L.J. 2004. The Role of Risk Analysis and Risk Management in Environmental Protection. Congressional Research Service. The Library of Congress, Washington DC.

Stulz, R. 1996. "Rethinking Risk Management.” Journal of Applied Corporate Finance. Fall. pp. 8-24.

The U.S. Nominal Coal Prices, 1949-2004. (Dollars per short ton), U.S. Energy Information Administration, http://www.eia.doe.gov/fuelcoal.html.

The U.S. Nominal Crude Oil Price, 1949-2004. (Dollars per barrel), U.S. Energy Information Administration, http://www.eia.doe.gov/oil_gas/petroleum/info_glance/petroleum.html for related information.

The U.S. Nominal Natural Gas Price, 1949-2004. (Dollars per Thousand Cubic Feet), U.S. Energy Information Administration. http://www.eia.doe.gov/oil_gas/natural_gas/info_glance/natural_gas.html for related information.

Tintner, G. 1965. Econometrics. 2rd. ed. John Wiley \& Sons, Inc, New York, NY.

Torries, T.F. 1998. Evaluating Mineral Projects: Applications and Misconceptions. Society for Mining Metallyrgy, and Exploration, Inc. Littleton, CO.

Venkataraman, V.K., and Driscoll, D.J. 1997. "Natural Gas to Liquids: An Overview.” U.S. Department of Energy, Federal Energy Technology Center. Washington, DC.

Williams, R.H., and Larson, E.D. 2003. "A Comparison of Direct and Indirect Liquefaction Technologies for Making Fluid Fuels from Coal.” Energy for Sustainable Development, Volume VII, No. 4, pp. 103-129.

Yoshimitsu, M. 2000. “The Present and Future of Coal from Viewpoint of 3Es.” Deputy General Manager \& Group Manager, International Cooperation Department, Coal Research Group. http://eneken.ieej.or.jp/en/data/pdf/192.pdf.

@Risk 4.5 Standard, Palisade Corporation, Ithaca, NY.

LIMDEP 7.0, Econometric Software, Inc., Plainview, NY. 


\section{Appendix}

Table A.1: The U.S. Nominal Coal Prices, 1949-2004. (Dollars per short ton)

\begin{tabular}{|c|c|c|c|c|}
\hline Year & Bituminous & Lignite Coal & Anthracite & Total Coal \\
\hline 1949 & 4.9 & 2.37 & 8.9 & 5.24 \\
\hline 1950 & 4.86 & 2.41 & 9.34 & 5.19 \\
\hline 1951 & 4.94 & 2.44 & 9.94 & 5.29 \\
\hline 1952 & 4.92 & 2.39 & 9.58 & 5.27 \\
\hline 1953 & 4.94 & 2.38 & 9.87 & 5.23 \\
\hline 1954 & 4.54 & 2.43 & 8.76 & 4.81 \\
\hline 1955 & 4.51 & 2.38 & 8 & 4.69 \\
\hline 1956 & 4.83 & 2.39 & 8.33 & 5.01 \\
\hline 1957 & 5.09 & 2.35 & 9.11 & 5.28 \\
\hline 1958 & 4.87 & 2.35 & 9.14 & 5.07 \\
\hline 1959 & 4.79 & 2.25 & 8.55 & 4.95 \\
\hline 1960 & 4.71 & 2.29 & 8.01 & 4.83 \\
\hline 1961 & 4.6 & 2.24 & 8.26 & 4.73 \\
\hline 1962 & 4.5 & 2.23 & 7.99 & 4.62 \\
\hline 1963 & 4.4 & 2.17 & 8.64 & 4.55 \\
\hline 1964 & 4.46 & 2.14 & 8.93 & 4.6 \\
\hline 1965 & 4.45 & 2.13 & 8.51 & 4.55 \\
\hline 1966 & 4.56 & 1.98 & 8.08 & 4.62 \\
\hline 1967 & 4.64 & 1.92 & 8.15 & 4.69 \\
\hline 1968 & 4.7 & 1.79 & 8.78 & 4.75 \\
\hline 1969 & 5.02 & 1.86 & 9.91 & 5.08 \\
\hline 1970 & 6.3 & 1.86 & 11.03 & 6.34 \\
\hline 1971 & 7.13 & 1.93 & 12.08 & 7.15 \\
\hline 1972 & 7.78 & 2.04 & 12.4 & 7.72 \\
\hline 1973 & 8.71 & 2.09 & 13.65 & 8.59 \\
\hline 1974 & 16.01 & 2.19 & 22.19 & 15.82 \\
\hline 1975 & 19.79 & 3.17 & 32.26 & 19.35 \\
\hline 1976 & 20.11 & 3.74 & 33.92 & 19.56 \\
\hline 1977 & 20.59 & 4.03 & 34.86 & 19.95 \\
\hline 1978 & 22.64 & 5.68 & 35.25 & 21.86 \\
\hline 1979 & 27.31 & 6.48 & 41.06 & 23.75 \\
\hline 1980 & 29.17 & 7.6 & 42.51 & 24.65 \\
\hline 1981 & 31.51 & 8.85 & 44.28 & 26.4 \\
\hline 1982 & 32.15 & 9.79 & 49.85 & 27.25 \\
\hline 1983 & 31.11 & 9.91 & 52.29 & 25.98 \\
\hline 1984 & 30.63 & 10.45 & 48.22 & 25.61 \\
\hline 1985 & 30.78 & 10.68 & 45.8 & 25.2 \\
\hline 1986 & 28.84 & 10.64 & 44.12 & 23.79 \\
\hline 1987 & 28.19 & 10.85 & 43.65 & 23.07 \\
\hline 1988 & 27.66 & 10.06 & 44.16 & 22.07 \\
\hline
\end{tabular}




\begin{tabular}{|c|c|c|c|c|}
\hline Year & Bituminous & Lignite Coal & Anthracite & Total Coal \\
\hline 1989 & 27.4 & 9.91 & 42.93 & 21.82 \\
\hline 1990 & 27.43 & 10.13 & 39.4 & 21.76 \\
\hline 1991 & 27.49 & 10.89 & 36.34 & 21.49 \\
\hline 1992 & 26.78 & 10.81 & 34.24 & 21.03 \\
\hline 1993 & 26.15 & 11.11 & 32.94 & 19.85 \\
\hline 1994 & 25.68 & 10.77 & 36.07 & 19.41 \\
\hline 1995 & 25.56 & 10.83 & 39.78 & 18.83 \\
\hline 1996 & 25.17 & 10.92 & 36.78 & 18.5 \\
\hline 1997 & 24.64 & 10.91 & 35.12 & 18.14 \\
\hline 1998 & 24.87 & 11.08 & 42.91 & 17.67 \\
\hline 1999 & 23.92 & 11.04 & 35.13 & 16.63 \\
\hline 2000 & 24.15 & 11.41 & 40.9 & 16.78 \\
\hline 2001 & 25.36 & 11.52 & 47.67 & 17.38 \\
\hline 2002 & 26.57 & 11.07 & 47.78 & 17.98 \\
\hline 2003 & 26.73 & 11.2 & 49.55 & 17.85 \\
\hline 2004 & 30.47 & 12.35 & 60.16 & 19.85 \\
\hline
\end{tabular}

(Source: U.S. Energy Information Administration) http://www.eia.doe.gov/fuelcoal.html. 
Table A.2: The U.S. Nominal Crude Oil Price, 1949-2004. (Dollars per barrel)

\begin{tabular}{|c|c|c|c|c|}
\hline$\underline{\text { Year }}$ & $\frac{\text { Alaska North }}{\text { Slope }}$ & $\underline{\text { California }}$ & $\underline{\text { Texas }}$ & $\underline{\text { U.S. Average }}$ \\
\hline 1949 & NA & NA & NA & 2.54 \\
\hline 1950 & NA & NA & NA & 2.51 \\
\hline 1951 & NA & NA & NA & 2.53 \\
\hline 1952 & NA & NA & NA & 2.53 \\
\hline 1953 & NA & NA & NA & 2.68 \\
\hline 1954 & NA & NA & NA & 2.78 \\
\hline 1955 & NA & NA & NA & 2.77 \\
\hline 1956 & NA & NA & NA & 2.79 \\
\hline 1957 & NA & NA & NA & 3.09 \\
\hline 1958 & NA & NA & NA & 3.01 \\
\hline 1959 & NA & NA & NA & 2.9 \\
\hline 1960 & NA & NA & NA & 2.88 \\
\hline 1961 & NA & NA & NA & 2.89 \\
\hline 1962 & NA & NA & NA & 2.9 \\
\hline 1963 & NA & NA & NA & 2.89 \\
\hline 1964 & NA & NA & NA & 2.88 \\
\hline 1965 & NA & NA & NA & 2.86 \\
\hline 1966 & NA & NA & NA & 2.88 \\
\hline 1967 & NA & NA & NA & 2.92 \\
\hline 1968 & NA & NA & NA & 2.94 \\
\hline 1969 & NA & NA & NA & 3.09 \\
\hline 1970 & NA & NA & NA & 3.18 \\
\hline 1971 & NA & NA & NA & 3.39 \\
\hline 1972 & NA & NA & NA & 3.39 \\
\hline 1973 & NA & NA & NA & 3.89 \\
\hline 1974 & NA & NA & NA & 6.87 \\
\hline 1975 & NA & NA & NA & 7.67 \\
\hline 1976 & NA & NA & NA & 8.19 \\
\hline 1977 & 6.29 & 7.92 & 8.58 & 8.57 \\
\hline 1978 & 5.21 & 8.58 & 9.29 & 9 \\
\hline 1979 & 10.57 & 12.78 & 12.65 & 12.64 \\
\hline 1980 & 16.87 & 23.87 & 21.84 & 21.59 \\
\hline 1981 & 23.23 & 26.8 & 35.06 & 31.77 \\
\hline 1982 & 19.92 & 24.58 & 31.77 & 28.52 \\
\hline 1983 & 17.69 & 22.61 & 29.35 & 26.19 \\
\hline 1984 & 17.91 & 22.09 & 28.87 & 25.88 \\
\hline 1985 & 16.98 & 22.14 & 26.8 & 24.09 \\
\hline
\end{tabular}




\begin{tabular}{|c|c|c|c|c|}
\hline Year & $\begin{array}{l}\text { Alaska North } \\
\underline{\text { Slope }}\end{array}$ & $\underline{\text { California }}$ & $\underline{\text { Texas }}$ & U.S. Average \\
\hline 1986 & 6.45 & 11.9 & 14.73 & 12.51 \\
\hline 1987 & 10.83 & 13.92 & 17.55 & 15.4 \\
\hline 1988 & 8.43 & 10.97 & 14.71 & 12.58 \\
\hline 1989 & 12 & 14.06 & 17.81 & 15.86 \\
\hline 1990 & 15.23 & 17.81 & 22.37 & 20.03 \\
\hline 1991 & 11.57 & 13.72 & 19.04 & 16.54 \\
\hline 1992 & 11.73 & 13.55 & 18.32 & 15.99 \\
\hline 1993 & 10.84 & 12.11 & 16.19 & 14.25 \\
\hline 1994 & 9.77 & 12.12 & 14.98 & 13.19 \\
\hline 1995 & 11.12 & 14 & 16.38 & 14.62 \\
\hline 1996 & 15.32 & 16.72 & 20.31 & 18.46 \\
\hline 1997 & 14.84 & 15.78 & 18.66 & 17.23 \\
\hline 1998 & 8.47 & 9.55 & 12.28 & 10.87 \\
\hline 1999 & 12.46 & 14.08 & 17.29 & 15.56 \\
\hline 2000 & 23.62 & 24.82 & 28.6 & 26.72 \\
\hline 2001 & 18.18 & 20.11 & 23.41 & 21.84 \\
\hline 2002 & 19.37 & 21.87 & 23.77 & 22.51 \\
\hline 2003 & 23.78 & 26.43 & 29.13 & 27.56 \\
\hline 2004 & 33.03 & 34.47 & 38.79 & 36.77 \\
\hline
\end{tabular}

(Source: U.S. Energy Information Administration)

http://www.eia.doe.gov/oil_gas/petroleum/info_glance/petroleum.html for related information. 
Table A.3: The U.S. Nominal Natural Gas Price, 1949-2004. (Dollars per Thousand Cubic Feet)

\begin{tabular}{|c|c|c|c|}
\hline Year & Wellhead & City Gate & Import \\
\hline$\overline{1949}$ & 0.06 & NA & NA \\
\hline 1950 & 0.07 & NA & NA \\
\hline 1951 & 0.07 & NA & NA \\
\hline 1952 & 0.08 & NA & NA \\
\hline 1953 & 0.09 & NA & NA \\
\hline 1954 & 0.1 & NA & NA \\
\hline 1955 & 0.1 & NA & NA \\
\hline 1956 & 0.11 & NA & NA \\
\hline 1957 & 0.11 & NA & NA \\
\hline 1958 & 0.12 & NA & NA \\
\hline 1959 & 0.13 & NA & NA \\
\hline 1960 & 0.14 & NA & NA \\
\hline 1961 & 0.15 & NA & NA \\
\hline 1962 & 0.16 & NA & NA \\
\hline 1963 & 0.16 & NA & NA \\
\hline 1964 & 0.15 & NA & NA \\
\hline 1965 & 0.16 & NA & NA \\
\hline 1966 & 0.16 & NA & NA \\
\hline 1967 & 0.16 & NA & NA \\
\hline 1968 & 0.16 & NA & NA \\
\hline 1969 & 0.17 & NA & NA \\
\hline 1970 & 0.17 & NA & NA \\
\hline 1971 & 0.18 & NA & NA \\
\hline 1972 & 0.19 & NA & 0.31 \\
\hline 1973 & 0.22 & NA & 0.35 \\
\hline 1974 & 0.3 & NA & 0.55 \\
\hline 1975 & 0.44 & NA & 1.21 \\
\hline 1976 & 0.58 & NA & 1.72 \\
\hline 1977 & 0.79 & NA & 1.98 \\
\hline 1978 & 0.91 & NA & 2.13 \\
\hline 1979 & 1.18 & NA & 2.49 \\
\hline 1980 & 1.59 & NA & 4.28 \\
\hline 1981 & 1.98 & NA & 4.88 \\
\hline 1982 & 2.46 & NA & 5.03 \\
\hline 1983 & 2.59 & NA & 4.78 \\
\hline 1984 & 2.66 & 3.95 & 4.08 \\
\hline 1985 & 2.51 & 3.75 & 3.21 \\
\hline 1986 & 1.94 & 3.22 & 2.43 \\
\hline 1987 & 1.67 & 2.87 & 1.95 \\
\hline 1988 & 1.69 & 2.92 & 1.84 \\
\hline 1989 & 1.69 & 3.01 & 1.82 \\
\hline
\end{tabular}




\begin{tabular}{|c|c|c|c|}
\hline Year & Wellhead & $\underline{\text { City Gate }}$ & Imports \\
\hline 1990 & 1.71 & 3.03 & 1.94 \\
\hline 1991 & 1.64 & 2.9 & 1.83 \\
\hline 1992 & 1.74 & 3.01 & 1.85 \\
\hline 1993 & 2.04 & 3.21 & 2.03 \\
\hline 1994 & 1.85 & 3.07 & 1.87 \\
\hline 1995 & 1.55 & 2.78 & 1.49 \\
\hline 1996 & 2.17 & 3.34 & 1.97 \\
\hline 1997 & 2.32 & 3.66 & 2.17 \\
\hline 1998 & 1.96 & 3.07 & 1.97 \\
\hline 1999 & 2.19 & 3.1 & 2.24 \\
\hline 2000 & 3.68 & 4.62 & 3.95 \\
\hline 2001 & 4 & 5.72 & 4.43 \\
\hline 2002 & 2.95 & 4.12 & 3.15 \\
\hline 2003 & 4.88 & 5.85 & 5.17 \\
\hline 2004 & 5.49 & 6.65 & 5.81 \\
\hline
\end{tabular}


Table A.4: Cushing, OK WTI Spot Price FOB (Dollars per Barrel)

\begin{tabular}{|c|c|c|c|c|c|}
\hline Week Of & Mon & Tue & $\underline{\text { Wed }}$ & Thu & Fri \\
\hline 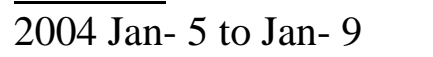 & $\overline{33.71}$ & 33.54 & $\overline{33.57}$ & $\overline{34.27}$ & 34.38 \\
\hline 2004 Jan-12 to Jan-16 & 34.92 & 34.26 & 34.62 & 33.61 & 35.16 \\
\hline 2004 Jan-19 to Jan-23 & & 36.21 & 35.53 & 35.12 & 34.94 \\
\hline 2004 Jan-26 to Jan-30 & 34.41 & 33.99 & 33.63 & 32.86 & 33.16 \\
\hline 2004 Feb- 2 to Feb- 6 & 34.02 & 34.20 & 33.06 & 33.26 & 32.49 \\
\hline 2004 Feb- 9 to Feb-13 & 32.91 & 34.03 & 33.93 & 34.03 & 34.51 \\
\hline 2004 Feb-16 to Feb-20 & & 35.13 & 35.42 & 35.81 & 35.80 \\
\hline 2004 Feb-23 to Feb-27 & 35.75 & 35.85 & 37.28 & 35.45 & 36.08 \\
\hline 2004 Mar- 1 to Mar- 5 & 36.85 & 36.60 & 35.80 & 36.81 & 37.31 \\
\hline 2004 Mar- 8 to Mar-12 & 36.53 & 36.29 & 36.21 & 36.95 & 36.21 \\
\hline 2004 Mar-15 to Mar-19 & 7.44 & 37.36 & 38.21 & 37.81 & 38.09 \\
\hline 2004 Mar-22 to Mar-26 & 37.12 & 37.81 & 37.06 & 35.67 & 35.61 \\
\hline 2004 Mar-29 to Apr- 2 & 35.41 & 36.15 & 35.75 & 34.47 & 34.3 \\
\hline 2004 Apr- 5 to Apr- 9 & 34.29 & 35.09 & 36.28 & 37.14 & \\
\hline 2004 Apr-12 to Apr-16 & 37.79 & 37.09 & 36.62 & 37.74 & 37.70 \\
\hline 2004 Apr-19 to Apr-23 & 37.46 & 37.61 & 36.61 & 37.70 & 37.22 \\
\hline 2004 Apr-26 to Apr-30 & 37.02 & 37.49 & 37.23 & 37.50 & 37.31 \\
\hline 2004 May- 3 to May- 7 & 38.26 & 38.86 & 39.69 & 39.41 & 39.98 \\
\hline 2004 May-10 to May-14 & 38.90 & 40.30 & 40.30 & 40.94 & 41.42 \\
\hline 2004 May-17 to May-21 & 41.53 & 40.32 & 41.61 & 40.92 & 39.83 \\
\hline 2004 May-24 to May-28 & 42.03 & 41.45 & 40.60 & 39.25 & 39.90 \\
\hline 2004 May-31 to Jun- 4 & & 42.33 & 39.96 & 39.29 & 38.4 \\
\hline 2004 Jun- 7 to Jun-11 & 38.72 & 37.18 & 37.60 & 38.45 & \\
\hline 2004 Jun-14 to Jun-18 & 37.58 & 37.18 & 37.33 & 38.51 & 38.68 \\
\hline 2004 Jun-21 to Jun-25 & 37.69 & 38.11 & 37.56 & 37.81 & 37.3 \\
\hline 2004 Jun-28 to Jul- 2 & 36.25 & 35.60 & 36.92 & 38.56 & 38.37 \\
\hline 2004 Jul- 5 to Jul- 9 & & 39.56 & 39.18 & 40.27 & 39.9 \\
\hline $2004 \mathrm{Jul}-12$ to Jul-16 & 39.30 & 39.55 & 40.98 & 40.70 & 41.1( \\
\hline $2004 \mathrm{Jul}-19$ to Jul-23 & 41.55 & 40.86 & 40.63 & 41.51 & 41.8 \\
\hline 2004 Jul-26 to Jul-30 & 41.45 & 41.83 & 42.81 & 42.69 & 43.72 \\
\hline $2004 \mathrm{~A}$ & 43.83 & 44.13 & 42.73 & 44.39 & 43.9 \\
\hline 2004 Aug- 9 to Aug-13 & 44.86 & 44.51 & 44.72 & 45.52 & 46.6 \\
\hline 2004 Aug-16 to Aug-20 & 46.02 & 46.75 & 47.36 & 48.66 & 47.60 \\
\hline 2004 Aug-23 to Aug-27 & 46.00 & 45.68 & 43.83 & 43.06 & 43.11 \\
\hline 2004 Aug-30 to Sep- 3 & 42.32 & 42.23 & 43.89 & 44.04 & 43.9 \\
\hline 200 & & & 42.77 & 44.53 & 42.8 \\
\hline $2004 S$ & 43.86 & 44.62 & 43.83 & 44.03 & 5.6 \\
\hline
\end{tabular}




\begin{tabular}{|c|c|c|c|c|c|}
\hline Week Of & Mon & Tue & $\underline{\text { Wed }}$ & Thu & Fri \\
\hline 2004 Sep-20 to Sep-24 & $\overline{46.33}$ & $\overline{47.11}$ & $\overline{48.41}$ & $\overline{48.37}$ & $\overline{48.86}$ \\
\hline 2004 Sep-27 to Oct- 1 & 49.56 & 49.76 & 49.53 & 49.56 & 50.16 \\
\hline 2004 Oct- 4 to Oct- 8 & 49.85 & 51.08 & 51.98 & 52.56 & 53.40 \\
\hline 2004 Oct-11 to Oct-15 & 53.65 & 53.49 & 53.86 & 54.69 & 54.89 \\
\hline 2004 Oct-18 to Oct-22 & 53.59 & 53.28 & 54.93 & 54.51 & 55.83 \\
\hline 2004 Oct-25 to Oct-29 & 55.52 & 56.37 & 52.52 & 50.95 & 51.78 \\
\hline 2004 Nov- 1 to Nov- 5 & 50.10 & 49.60 & 50.90 & 48.80 & 49.65 \\
\hline 2004 Nov- 8 to Nov-12 & 49.10 & 47.40 & 48.70 & 47.50 & 47.30 \\
\hline 2004 Nov-15 to Nov-19 & 46.95 & 46.10 & 46.85 & 46.30 & 48.90 \\
\hline 2004 Nov-22 to Nov-26 & 48.48 & 48.74 & 49.14 & & \\
\hline 2004 Nov-29 to Dec- 3 & 49.71 & 49.16 & 45.56 & 43.31 & 42.56 \\
\hline 2004 Dec- 6 to Dec-10 & 42.96 & 41.51 & 41.96 & 42.41 & 40.71 \\
\hline 2004 Dec-13 to Dec-17 & 41.06 & 41.76 & 44.21 & 44.16 & 46.31 \\
\hline 2004 Dec-20 to Dec-24 & 45.57 & 45.76 & 44.05 & 42.19 & \\
\hline 2004 Dec-27 to Dec-31 & 41.26 & 41.78 & 43.69 & 43.36 & \\
\hline 2005 Jan- 3 to Jan- 7 & 42.16 & 43.96 & 43.41 & 45.51 & 45.32 \\
\hline 2005 Jan-10 to Jan-14 & 45.31 & 45.66 & 46.46 & 48.11 & 48.41 \\
\hline 2005 Jan-17 to Jan-21 & & 48.46 & 47.61 & 47.01 & 48.31 \\
\hline 2005 Jan-24 to Jan-28 & 48.61 & 49.43 & 48.80 & 48.80 & 47.15 \\
\hline 2005 Jan-31 to Feb- 4 & 48.25 & 47.10 & 46.65 & 46.40 & 46.45 \\
\hline 2005 Feb- 7 to Feb-11 & 45.35 & 45.40 & 45.45 & 47.05 & 47.15 \\
\hline 2005 Feb-14 to Feb-18 & 47.50 & 47.30 & 48.35 & 47.50 & 48.45 \\
\hline 2005 Feb-21 to Feb-25 & & 51.00 & 51.73 & 52.05 & 52.20 \\
\hline 2005 Feb-28 to Mar- 4 & 51.75 & 51.67 & 53.00 & 53.60 & 53.70 \\
\hline 2005 Mar- 7 to Mar-11 & 53.90 & 54.55 & 54.75 & 53.52 & 54.40 \\
\hline 2005 Mar-14 to Mar-18 & 54.90 & 55.05 & 56.50 & 56.40 & 56.80 \\
\hline 2005 Mar-21 to Mar-25 & 56.70 & 55.95 & 49.43 & 49.70 & \\
\hline 2005 Mar-28 to Apr- 1 & 54.06 & 54.26 & 53.96 & 55.31 & 57.26 \\
\hline 2005 Apr- 4 to Apr- 8 & 56.86 & 55.83 & 55.88 & 54.16 & 53.46 \\
\hline 2005 Apr-11 to Apr-15 & 53.71 & 51.54 & 50.21 & 51.11 & 50.61 \\
\hline 2005 Apr-18 to Apr-22 & 50.52 & 52.33 & 52.45 & 52.49 & 54.16 \\
\hline 2005 Apr-25 to Apr-29 & 53.16 & 54.33 & 51.37 & 51.92 & 49.20 \\
\hline 2005 May- 2 to May- 6 & 50.94 & 49.60 & 50.22 & 51.12 & 51.30 \\
\hline 2005 May- 9 to May-13 & 52.04 & 51.76 & 50.39 & 48.83 & 48.65 \\
\hline 2005 Мay-16 to May-20 & 48.64 & 48.97 & 46.99 & 47.00 & 47.25 \\
\hline 2005 Мay-23 to May-27 & 48.68 & 49.14 & 50.37 & 50.89 & 51.65 \\
\hline 2005 May-30 to Jun- 3 & & 52.08 & 54.40 & 53.46 & 55.08 \\
\hline 2005 Jun- 6 to Jun-10 & 54.46 & 53.84 & 52.51 & 54.36 & 53.55 \\
\hline
\end{tabular}




\begin{tabular}{|c|c|c|c|c|c|}
\hline$\underline{\text { Week Of }}$ & $\underline{\text { Mon }}$ & $\underline{\text { Tue }}$ & $\underline{\text { Wed }}$ & $\underline{\text { Thu }}$ & $\underline{\text { Fri }}$ \\
\hline 2005 Jun-13 to Jun-17 & 55.47 & 55.03 & 55.53 & 56.48 & 30. \\
\hline 2005 Jun-20 to Jun-24 & 59.19 & 58.90 & 58.27 & 59.23 & 59.63 \\
\hline 2005 Jun-27 to Jul- 1 & 59.78 & 58.32 & 57.23 & 56.63 & 59.11 \\
\hline 2005 Jul- 4 to Jul- 8 & & 59.71 & 61.24 & 60.76 & 59.71 \\
\hline 2005 Jul-11 to Jul-15 & 59.23 & 60.49 & 60.00 & 57.83 & 58.36 \\
\hline $2005 \mathrm{Jul}-18$ to Jul-22 & 57.12 & 57.61 & 56.73 & 57.31 & ני. \\
\hline 2005 Jul-25 to Jul-29 & 58.16 & 59.05 & 59.12 & 59.91 & 60.71 \\
\hline 2005 Aug- 1 to Aug- 5 & 61.51 & 61.87 & 60.76 & 61.60 & 2.44 \\
\hline 2005 Aug- 8 to Aug-12 & 63.92 & 63.13 & 64.80 & 65.67 & 66.71 \\
\hline 2005 Aug-15 to Aug-19 & 66.21 & 66.11 & 63.29 & 63.47 & 65.51 \\
\hline 2005 Aug-22 to Aug-26 & 65.46 & 65.81 & 67.10 & 67.29 & 6.05 \\
\hline 2005 Aug-29 to Sep- 2 & 67.41 & 69.91 & 68.63 & 69.50 & 6.91 \\
\hline 2005 Sep- 5 to Sep- 9 & & 65.83 & 64.38 & 64.80 & 64.21 \\
\hline 2005 Sep-12 to Sep-16 & 63.29 & 63.18 & 65.20 & 64.64 & 62.91 \\
\hline 2005 Sep-19 to Sep-23 & 67.21 & 66.24 & 66.96 & 67.07 & 64.67 \\
\hline 2005 Sep-26 to & 65.98 & 64.94 & 66.36 & 66.83 & 00.21 \\
\hline 2005 Oct- 3 to Oct- 7 & 65.36 & 63.74 & 62.56 & 61.81 & 61.81 \\
\hline 2005 Oct-10 to Oct-14 & 60.71 & 63.84 & 64.13 & 63.05 & 62.61 \\
\hline 2005 Oct- 17 to Oct-21 & 64.26 & 62.94 & 62.11 & 61.04 & 61.05 \\
\hline 2005 Oct-24 to Oct-28 & 60.63 & 62.83 & 60.85 & 61.03 & 61.30 \\
\hline 2005 Oct-31 to Nov- 4 & 59.80 & 59.85 & 59.75 & 61.70 & 60.60 \\
\hline 2005 Nov- 7 to Nov-11 & 59.40 & 59.70 & 59.65 & 57.80 & 57.45 \\
\hline 2005 Nov-14 to Nov-18 & 57.60 & 57.05 & 57.85 & 56.20 & 56.30 \\
\hline 2005 Nov-21 to Nov-25 & 57.75 & 58.30 & 58.35 & & \\
\hline 2005 Nov-28 to Dec- 2 & 57.36 & 56.46 & 57.33 & 58.46 & 59.31 \\
\hline 2005 Dec- 5 to Dec- 9 & 59.91 & 59.96 & 59.21 & 60.66 & 59.41 \\
\hline 2005 Dec-12 to Dec-16 & 61.36 & 61.36 & 60.86 & 60.01 & $58 .($ \\
\hline 2005 Dec-19 to Dec-23 & 57.31 & 57.81 & 58.56 & 58.08 & 58.08 \\
\hline 2005 Dec-26 to Dec-30 & & 58.16 & 59.81 & 60.26 & 61.06 \\
\hline 2006 Jan- 2 to Jan- 6 & & 63.11 & 63.41 & 62.81 & 64.21 \\
\hline 2006 Jan- 9 to Jan-13 & 63.56 & 63.41 & 63.91 & 63.96 & 63.86 \\
\hline 2006 Jan-16 to Jan-20 & & 66.36 & 65.76 & 66.86 & 68.16 \\
\hline 2006 Jan-23 to Jan-27 & 68.06 & 66.83 & 65.60 & 65.80 & 67.81 \\
\hline 2006 Jan-30 to Feb- 3 & 68.36 & 67.86 & 66.61 & 64.71 & 65.41 \\
\hline 2006 Feb- 6 to Feb-10 & 65.11 & 63.01 & 62.51 & 62.66 & 62.01 \\
\hline 2006 Feb-13 to Feb-17 & 61.26 & 59.61 & & & \\
\hline
\end{tabular}

(Source: U.S. Energy Information Administration); http://tonto.eia.doe.gov/dnav/pet/hist/rwtcd.htm 